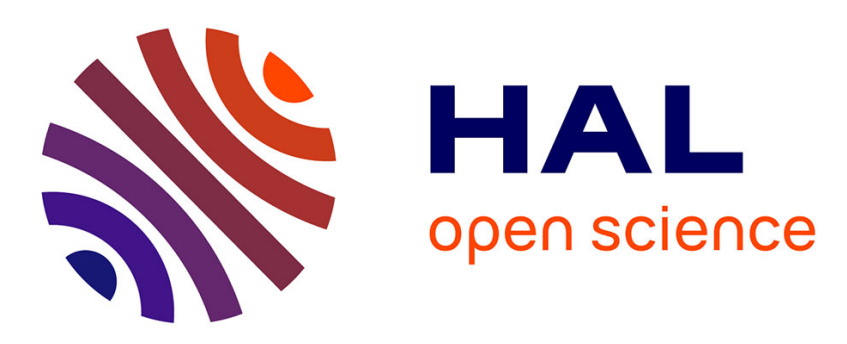

\title{
The microbial carbon pump concept: Potential biogeochemical significance in the globally changing ocean
}

Louis Legendre, Richard B. Rivkin, Markus G Weinbauer, Lionel Guidi, Julia Uitz

\section{To cite this version:}

Louis Legendre, Richard B. Rivkin, Markus G Weinbauer, Lionel Guidi, Julia Uitz. The microbial carbon pump concept: Potential biogeochemical significance in the globally changing ocean. Progress in Oceanography, 2015, 134, pp.432-450. 10.1016/j.pocean.2015.01.008 . hal-01120262

\section{HAL Id: hal-01120262 https://hal.sorbonne-universite.fr/hal-01120262}

Submitted on 25 Feb 2015

HAL is a multi-disciplinary open access archive for the deposit and dissemination of scientific research documents, whether they are published or not. The documents may come from teaching and research institutions in France or abroad, or from public or private research centers.
L'archive ouverte pluridisciplinaire HAL, est destinée au dépôt et à la diffusion de documents scientifiques de niveau recherche, publiés ou non, émanant des établissements d'enseignement et de recherche français ou étrangers, des laboratoires publics ou privés. 


\section{Review}

The microbial carbon pump concept: potential biogeochemical significance in the globally changing ocean

\section{POSSIBLE ALTERNATIVE TITLE}

The microbial carbon pump concept: potential biogeochemical significance in the context of the biological and carbonate pumps and in the globally changing ocean

\section{Louis Legendre ${ }^{\mathrm{a}, \mathrm{b}, *}$, Richard B. Rivkin ${ }^{\mathrm{c}}$, Markus Weinbauer ${ }^{\mathrm{a}, \mathrm{b}}$, Lionel Guidi ${ }^{\mathrm{a}, \mathrm{b}}$, Julia} $\mathrm{Uitz}^{\mathrm{a}, \mathrm{b}}$

a Sorbonne Universités, UPMC Univ. Paris 06, UMR 7093, Laboratoire d'Océanographie de Villefranche, 06230 Villefranche-sur-Mer, France

${ }^{\text {b }}$ CNRS, UMR 7093, Laboratoire d'Océanographie de Villefranche, 06230 Villefranche-surMer, France

${ }^{\mathrm{c}}$ Department of Ocean Sciences, Memorial University of Newfoundland, St. John's, NF A1C 5S7, Canada

* Corresponding author. Tel.: +33493763836

E-mail addresses: legendre@obs-vlfr.fr (L. Legendre), rrivkin@mun.ca (R.B. Rivkin), wein@obs-vlfr.fr $(M ;$ Weinbauer), lguidi@obs-vlfr.fr (L. Guidi), uitz@obs-vlfr.fr (J. Uitz) 


\section{Contents}

1. Introduction

2. The three vertical ocean carbon pumps

3. Ocean carbon sequestration

4. DOC fractions and the microbial carbon pump

4.1. DOC fractions: lifetimes and production rates

4.2. The microbial carbon pump: microbiological concept and biogeochemical units

5. Comparison of the microbial and vertical ocean carbon pumps

5.1. The microbial and solubility carbon pumps

5.2. The microbial and biological carbon pumps

6. Review of reports of refractory dissolved organic carbon processes in the ocean

6.1. Production of refractory dissolved organic carbon in the ocean

6.2. Removal of refractory dissolved organic carbon in the ocean

6.3. Vertical redistribution of the longer-lived dissolved organic carbon fractions

7. Potential effects of climate change on the microbial carbon pump

7.1. Increased surface-ocean temperature

7.2. Increased water-column stratification

7.3. Change in the concentration of particulate organic matter

7.4. Changes in thermohaline circulation and cloud cover

7.5. Ocean acidification

7.6. Overall potential effects of climate change on the microbial carbon pump

8. Conclusions

Acknowledgements

References 


\section{ABSTRACT}

Three vertical ocean carbon pumps have been known for almost three decades to sequester atmospheric carbon in the deep-water and sediment reservoirs, i.e. the solubility pump, the carbonate pump, and the soft-tissue (also known as organic, or biological) carbon pump (BCP). These three pumps maintain the vertical gradient in total dissolved inorganic carbon between the surface and deep waters. The more recently proposed microbial carbon pump (MCP) would maintain a gradient between short- and long-lived dissolved organic carbon (DOC; average lifetimes of $<100$ and $>100$ years, respectively). Long-lived DOC is an additional proposed reservoir of sequestered carbon in the ocean. This review: examines critically aspects of the vertical ocean carbon pumps and the MCP, in particular their physical dimensions and their potential roles in carbon sequestration; normalises the dimensions of the MCP to allow direct comparisons with the three vertical ocean carbon pumps; compares the $\mathrm{MCP}$ and vertical ocean carbon pumps; organises in a coherent framework the information available in the literature on refractory DOC; explores the potential effects of the globally changing ocean on the MCP; and identifies the assumptions that generally underlie the MCP studies, as bases for future research. The study: proposes definitions of terms, expressions and concepts related to the four ocean carbon pumps (i.e. three vertical pumps and MCP); defines the magnitude for the MCP as the rate of production of DOC with an average lifetime of $>100$ years and provides its first estimate for the World Ocean, i.e. 0.2 $\mathrm{Pg} \mathrm{C}_{\text {year }}{ }^{-1}$; and introduces an operational "first-time-sequestration" criterion that prevents organic carbon fluxes from being assigned to both the $\mathrm{BCP}$ and the MCP. In our review of the potential effects of predicted climate-related changes in the ocean environment on the MCP, we found that three of the seven predicted changes could potentially enhance carbon sequestration by the MCP, and three could diminish it. 


\section{Keywords}

microbial carbon pump; biological carbon pump; carbonate pump; dissolved organic carbon; carbon cycle; climatic changes 


\section{Introduction}

In the World Ocean, there is a strong vertical gradient in the concentration of dissolved $\mathrm{CO}_{2}$, and there are several different forms that make up total dissolved inorganic carbon $\left(C_{\mathrm{T}}\right)$ :

$$
C_{\mathrm{T}}=\mathrm{CO}_{2}(\text { dissolved })+\mathrm{H}_{2} \mathrm{CO}_{3}+\mathrm{HCO}_{3}{ }^{-}+\mathrm{CO}_{3}{ }^{2-}
$$

where $\mathrm{H}_{2} \mathrm{CO}_{3}, \mathrm{HCO}_{3}{ }^{-}$and $\mathrm{CO}_{3}{ }^{2-}$ are carbonic acid, and bicarbonate and carbonate ions, respectively. In the literature, $C_{\mathrm{T}}$ is also called dissolved inorganic carbon (DIC) and total $\mathrm{CO}_{2}\left(\mathrm{TCO}_{2}\right.$ or $\left.\sum \mathrm{CO}_{2}\right)$. The global mean $C_{\mathrm{T}}$ in deep waters below $1200 \mathrm{~m}$ is higher than in the surface mixed layer, i.e. 2284 and $2012 \mu \mathrm{mol} \mathrm{kg}^{-1}$, respectively (Volk and Hoffert, 1985, and Fig. 1). This requires that physical, chemical and biological processes counteract the continuous erosion by diffusive ocean mixing (on timescale of $\sim 1000$ years) of the vertical differences in the concentration of $C_{\mathrm{T}}$. Volk and Hoffert (1985) referred to the processes that maintain the $C_{\mathrm{T}}$ gradient in the World Ocean as the "ocean carbon pumps", and these pumps have an important effect on the air-sea $\mathrm{CO}_{2}$ fluxes on century timescales (IPCC, 2013, Section 6.3.2.5.5).

In their seminal paper, Volk and Hoffert (1985) defined three vertical ocean carbon pumps, corresponding to different forms of carbon in the marine environment: the solubility pump for $C_{\mathrm{T}}$, the carbonate pump for particulate inorganic carbon $\left(\mathrm{CaCO}_{3}\right)$, and the soft-tissue pump (also called organic carbon pump, but more generally biological carbon pump) for particulate organic carbon (POC) although this pump can also include dissolved organic carbon (DOC). The expression "biological carbon pump" (BCP) refers to either the organic component of the ocean carbon pump only, or both the organic and $\mathrm{CaCO}_{3}$ components. Volk and Hoffert (1985) and Passow and Carlson (2012) used biological carbon pump for the sum of the two components. In this review, BCP refers only to the organic component, consistent with the Glossary in IPCC (2013, Annex III).

Recently, another ocean carbon pump, called the microbial carbon pump (MCP), was proposed by Jiao and collaborators (Jiao et al., 2010; Jiao and Azam, 2011; Jiao et al., 2011). The MCP concept was developed within the context of marine microbiology with proposed links with marine biogeochemistry. A key assumption of the MCP is that the production mechanisms of long-lived DOC in the ocean are largely microbial. In contrast, the BCP concept was mostly developed, studied and modelled within the context of marine food webs and ocean biogeochemistry. The BCP has been central to studies that explore the present and future responses of biogeochemical fluxes to the globally changing ocean, which are critical 
to help inform governmental policy decisions (e.g. Passow and Carlson, 2012). If the oceanographic community is to consider the MCP along with the other ocean carbon pumps in assessments of the biologically mediated biogeochemical fluxes of carbon in the changing ocean, it is important that the MCP concept be expressed in the same units as the three other ocean carbon pumps (i.e. normalised).

Although well accepted now, the three vertical ocean carbon pumps were, at their origin, conceptual constructions that were based on a few observations and aimed at providing frameworks for the development and testing of hypotheses and models. This was clear in the seminal paper of Volk and Hoffert (1985), e.g. "distinguishing the strengths and efficiencies of the pumps may help formulate questions about models and possible ocean changes in the future". Similarly in the recent paper of Jiao et al. (2010), the authors proposed "the microbial carbon pump as a conceptual framework to address the role of microbial generation of RDOM and relevant carbon storage". The vertical ocean carbon pumps concept was proposed almost 30 years ago whereas the MCP concept is quite recent, hence the first now rests on extensive quantitative evidence (e.g. Sarmiento and Gruber, 2006) and has produced well accepted numerical models (e.g. Kwon et al., 2009), whereas the second (e.g. DeVries et al., 2014) is still largely hypothetical.

In the literature, expressions such as ocean carbon pump (biological, carbonate, organic, soft tissue, or solubility), carbon export and carbon sequestration are often used by authors differently, hence potentially creating confusion. Here, we propose and define a coherent set of expressions for use by the research community. The acronyms and symbols of quantities, their definitions and areal dimensions, and the corresponding units are summarised in Table 1. For easy reference, the definitions proposed in the text are assembled in a logical framework in Table 2, and schematised in Fig. 2. Our definitions are largely consistent with those of Passow and Carlson (2012). For the different fractions of dissolved organic carbon, we use the definitions proposed by Hansell (2013). Because our study examines ocean carbon pumps, we will refer below to DOC and POC instead of dissolved and particulate organic matter (DOM and POM, respectively).

A recent paper by Jiao et al. (2014) presented a general overview of the field and addressed future research directions for studies on the MCP based primarily on microbiological considerations. The objectives of the present in depth review are sequentially to: (1) critically examine key aspects of the vertical ocean carbon pumps, in particular their physical dimensions and their roles in carbon sequestration; (2) critically examine key aspects 
of the MCP, and normalise its dimensions to allow direct comparisons with the three vertical ocean carbon pumps; (3) compare the MCP with the vertical ocean carbon pumps;

(4) organise in a coherent framework the information available on refractory dissolved organic carbon; (5) explore the potential effects of the globally changing ocean on the MCP; and (6) identify the assumptions that generally underlie the MCP studies, as bases for future research.

In the following sections, we briefly describe and compare the functioning of the three vertical ocean carbon pumps, and examine carbon sequestration in the ocean, the DOC fractions and the microbial carbon pump. We then compare the microbial and the vertical ocean carbon pumps, review reports of refractory dissolved organic carbon processes in the ocean, and examine potential effects of climate change on the microbial carbon pump. We conclude by reviewing the main assumptions found in the major publications on the MCP.

\section{The three vertical ocean carbon pumps}

The carbon processed by the three vertical ocean carbon pumps originates in the atmosphere. The dissolution of atmospheric $\mathrm{CO}_{2}$ into the upper ocean is represented by downwardpointing arrow in Fig. 2 (the numbers in full or open circles in this section refer to arrows in Fig. 2). The steps of the solubility pump are as follows. Firstly, dissolved atmospheric $\mathrm{CO}_{2}$ in surface waters combines with water molecules $\left(\mathrm{H}_{2} \mathrm{O}\right)$, which produces bicarbonate and carbonate ions $\left(\mathrm{HCO}_{3}{ }^{-}\right.$and $\mathrm{CO}_{3}{ }^{2-}$, respectively) and protons $\left(\mathrm{H}^{+}\right)$:

$$
\mathrm{CO}_{2}+\mathrm{H}_{2} \mathrm{O} \leftrightarrow \mathrm{HCO}_{3}^{-}+\mathrm{H}^{+} \leftrightarrow \mathrm{CO}_{3}^{2-}+2 \mathrm{H}^{+}
$$

This modifies the $\mathrm{pH}$ of seawater. Conversely, dissolved $\mathrm{CO}_{2}$ may also be released to the atmosphere (reverse of eq. 2). Secondly, the dissolution of $\mathrm{CO}_{2}$ in surface waters is followed by deep mixing of the $\mathrm{CO}_{2}$-rich water, which is represented by downward-pointing arrow in Fig. 2 (labelled "solubility carbon pump"). Deep mixing occurs at high latitudes in winter in areas of deep convection, which include the North Atlantic Nordic Seas and the Weddell Sea in the Southern Ocean.

The carbonate pump (i.e. the expression introduced by Volk and Hoffert, 1985) is also called carbonate counter-pump (e.g. Heinze et al., 1991; Zeebe, 2012), because the precipitation of $\mathrm{CaCO}_{3}$ in the ocean is accompanied by the release of $\mathrm{CO}_{2}$ to surrounding waters, and thus the atmosphere, as shown by the calcification equation:

$$
\mathrm{Ca}^{2+}+2 \mathrm{HCO}_{3}^{-} \rightarrow \mathrm{CaCO}_{3}+\mathrm{CO}_{2}+\mathrm{H}_{2} \mathrm{O}
$$


Equation 3 shows that the carbonate pump both releases $\mathrm{CO}_{2}$ to the surrounding waters, and from there to the atmosphere, and precipitates $\mathrm{CaCO}_{3}$, thus creating bio-mineral particles that could sink to depth. In the ocean, there is release of ca. 0.6 mole of $\mathrm{CO}_{2}$ into the surrounding water and the atmosphere for each mole of $\mathrm{CaCO}_{3}$ precipitated, different from theoretical eq. 3 where $\mathrm{CO}_{2}: \mathrm{CaCO}_{3}=1.0$ (Ware et al., 1992; Frankignoulle et al., 1994). On the one hand, the release of $\mathrm{CO}_{2}$ from the upper-water-column to the atmosphere (represented by upward-pointing arrow in Fig. 2) decreases sea-surface $C_{\mathrm{T}}$. On the other hand, the sinking of $\mathrm{CaCO}_{3}$ particles (represented by downward-pointing arrow in Fig. 2; labelled "carbonate pump") and their dissolution at depth, which releases $\mathrm{HCO}_{3}{ }^{-}$(reverse of eq. 3 ; represented by rightward-pointing arrow in Fig. 2), increase deep-water $C_{\mathrm{T}}$. The depth at which $\mathrm{CaCO}_{3}$ particles dissolve depends on the crystal form of the mineral (i.e. aragonite or calcite, the first dissolves more rapidly than the second) and several environmental factors, mostly hydrostatic pressure and water temperature (more dissolution at higher pressure, i.e. greater depth, and lower temperature). A more complete treatment of carbonate chemistry can be found in Zeebe (2012). The two effects of the carbonate pump, i.e. decreasing $C_{\mathrm{T}}$ at surface and increasing it at depth, contribute to maintain the vertical $C_{\mathrm{T}}$ gradient.

The carbonate pump also creates a vertical gradient in total alkalinity $\left(A_{\mathrm{T}}\right.$, or TA; Fig. 1):

$$
A_{\mathrm{T}}=\left[\mathrm{HCO}_{3}^{-}\right]+2\left[\mathrm{CO}_{3}{ }^{2-}\right]+\left[\mathrm{B}(\mathrm{OH})_{4}^{-}\right]+\left[\mathrm{OH}^{-}\right]-\left[\mathrm{H}^{+}\right]+\text {minor compounds }
$$

$A_{\mathrm{T}}$ is a measure of the balance of electric charges in seawater. The list of minor compounds in eq. 4 can be found in Dickson (1981). The addition (or removal) of $\mathrm{CO}_{2}$ to seawater has no direct effect on $A_{\mathrm{T}}$ because the net reaction produces the same number of equivalents of $\mathrm{H}^{+}$as of $\mathrm{HCO}_{3}{ }^{-}$and/or $\mathrm{CO}_{3}{ }^{2-}$ (eq. 2). Calcification at surface decreases $A_{\mathrm{T}}$ by consuming $\mathrm{HCO}_{3}^{-}$(eq. 3), which reduces the ability of surface waters to absorb atmospheric $\mathrm{CO}_{2}$ (eq. 2). Conversely, the dissolution of $\mathrm{CaCO}_{3}$ at depth releases $\mathrm{HCO}_{3}{ }^{-}$(reverse of eq. 3), which increases both $A_{\mathrm{T}}$ and the ability of deep waters to absorb atmospheric $\mathrm{CO}_{2}$ (eq. 2) when these are brought back to the surface (at the timescale of the ocean circulation, i.e. ca. 1000 years). The sinking of carbonate particles is represented by downward-pointing arrow in Fig. 2 (labelled "carbonate pump"), and the water-column $\mathrm{CO}_{2}$ release by rightward-pointing arrow in Fig. 2. The carbonate pump is also called alkalinity pump.

The first step of the BCP is the photosynthetic uptake of inorganic carbon and synthesis of organic carbon by phytoplankton, i.e. primary production (PP). The resulting organic 
matter is transformed (e.g. lysis, grazing, respiration, incorporation into larger particles) by the pelagic food web in the euphotic zone, and the POC and DOC that are not remineralised (i.e. decomposed, respired) in the upper water column (i.e. ca. $100 \mathrm{~m}$ ) are exported downwards below the euphotic zone or the seasonal surface mixed layer, or are exported laterally. The exported organic carbon that is not remineralised during its downward transit through the mesopelagic layer (also called the twilight zone) is transferred into deep ocean waters. These various steps are represented in Fig. 2: upper-water-column synthesis DOC and POC (equation above the carbon pumps) and carbon respiration by the food web (rightwardpointing arrow ${ }^{-1}$ ), loss of some respiratory carbon to the atmosphere (upward-pointing arrow ), downward export of organic carbon (downward-pointing arrow labelled "biological carbon pump"), and water-column $\mathrm{CO}_{2}$ release (rightward-pointing arrow More detailed information on the BCP can be found in Sigman and Haug (2003), Honjo et al. (2014) and Turner (2014).

Even if the removal of $\mathrm{CO}_{2}$ by photosynthesis and its addition by respiration have no direct effect on $A_{\mathrm{T}}$ (see above), these two processes are accompanied by the assimilation (anabolism) or dissimilation (catabolism) of $\mathrm{NH}_{4}{ }^{+}, \mathrm{NO}_{3}{ }^{-}$, and $\mathrm{HPO}_{4}{ }^{2+}$, which liberate or take up $\mathrm{OH}^{-}$or $\mathrm{H}^{+}$(or take up $\mathrm{H}$ or $\mathrm{OH}^{-}$). As a result, photosynthesis is accompanied by a net increase in $A_{\mathrm{T}}$, and respiration by a net decrease (Gattuso et al., 1999, their eqs. 2a and 2b).

The general mechanism of the three vertical ocean carbon pumps includes both the downward export of carbon from the surface ocean (defined here as the deepest of either the base of the euphotic zone or the base of the seasonal surface mixed layer), and the downward transfer of the exported carbon into deep waters (i.e. below the maximum depth of the permanent pycnocline of ca. $1000 \mathrm{~m}$ ). The permanent pycnocline, also called intermediate layer, is the stable density gradient that separates the surface mixed layer and the deep waters, and extends from about 200-300 $\mathrm{m}$ in the open ocean down to ca. $1000 \mathrm{~m}$. This depth of $1000 \mathrm{~m}$ is operationally equivalent to the $1200 \mathrm{~m}$ depth horizon that separates the upper water column with an average $C_{\mathrm{T}}$ concentration of $2012 \mu \mathrm{mol} \mathrm{kg}^{-1}$ from the deep waters with $2284 \mu \mathrm{mol} \mathrm{kg}^{-1}$ (Volk and Hoffert, 1985). In this review, the downward transfer of carbon from the surface ocean that does not reach deep waters (i.e. bottom of the permanent pycnocline) is called "carbon export". The vertical carbon pumps (sensu stricto, Volk and Hoffert, 1985) maintain the vertical $C_{\mathrm{T}}$ gradient by transferring (and thus effectively sequestering) carbon below the permanent pycnocline. 
The physical dimensions of the three vertical ocean carbon pumps are $\left[\mathrm{ML}^{-2} \mathrm{~T}^{-1}\right]$, and the units in most oceanographic studies are $\mathrm{g} \mathrm{C} \mathrm{m}^{-2}$ year $^{-1}$ or mol $\mathrm{C} \mathrm{m}^{-2}$ year $^{-1}$, or for the whole ocean, Pg C year ${ }^{-1}$ or Gt $\mathrm{C}$ year ${ }^{-1}$ or Pmol C year ${ }^{-1}$. The solubility, carbonate and biological pumps transfer downwards $\mathrm{DIC}, \mathrm{CaCO}_{3}$ and organic carbon, respectively, and the carbonate pump also transfers upwards $\mathrm{CO}_{2}$ to the atmosphere. Because the dissociation of $\mathrm{CaCO}_{3}$ at depth produces $\mathrm{HCO}_{3}{ }^{-}$(eq. 3), and organic carbon in deep waters is ultimately remineralised to $\mathrm{CO}_{2}$, the compounds transferred vertically by the three pumps contribute to maintain the vertical $C_{\mathrm{T}}$ gradient. The magnitude of the solubility pump is the rate of DIC transfer to depth. In contrast, the magnitude of the carbonate pump is the rate of transfer of $\mathrm{CaCO}_{3}$ (and the $\mathrm{HCO}_{3}{ }^{-}$resulting from its dissociation) into deep waters plus the rate of transfer of $\mathrm{CO}_{2}$ into the atmosphere (eq. 3). The two terms are added together because the downward transfer of $\mathrm{CaCO}_{3}$ increases $C_{\mathrm{T}}$ in deep waters and the release of $\mathrm{CO}_{2}$ to the atmosphere decreases $C_{\mathrm{T}}$ in surface waters, i.e. the combination of the two processes strengthens the vertical $C_{\mathrm{T}}$ gradient, which corresponds to the definition of ocean carbon pump given above (Volk and Hoffert, 1985). The magnitude of the biological pump is the rate of transfer of organic carbon (and the $\mathrm{CO}_{2}$ resulting from its remineralisation) to depth.

The above paragraphs described the effects of the three vertical ocean carbon pumps on $C_{\mathrm{T}}$ and $A_{\mathrm{T}}$ separately. In Fig. 3, we illustrate the combined effects of the carbon pumps on these two variables. This figure was modified from Zeebe and Wolf-Gladrow (2008; their Fig 2), which illustrated the carbonate chemistry of a water parcel in the surface ocean. In our Fig 3, we added the combined effects of the above three pumps and the MCP (to be fully described in Section 4.2) on $C_{\mathrm{T}}$ and $A_{\mathrm{T}}$. Heterotrophic respiration was included in the original diagram of Zeebe and Wolf-Gladrow (2008) and is also part of our Fig. 3 because of its direct effect on $C_{\mathrm{T}}$ and its indirect effect on $A_{\mathrm{T}}$ (see above). In our application of the diagram to the carbon pumps, we explicitly associate respiration with the biologically-driven ocean carbon pumps (i.e. carbonate pump, BCP and MCP). It could be argued that respiration is not part of the carbon pumps because respiration is a general characteristic of all living organisms, and the fraction of carbon that is respired and returned to the atmosphere is not transferred to depth or the long-lived DOC by the ocean carbon pumps. However, heterotrophic respiration is the catabolic component of many of the biological processes that contribute to the carbon transformations in the biologically-driven carbon pumps, and is thus associated with them. Our approximate allocation, in Fig. 3, of fractions of total heterotrophic respiration to the various biologically-driven carbon pumps does not mean that all processes involved in the 
pumps necessarily are accompanied by heterotrophic respiration, but instead that all components of heterotrophic respiration accompany processes that are related directly or indirectly to the various biologically-driven ocean carbon pumps. In Fig. 3, the vertical distribution of $C_{\mathrm{T}}$ is affected by the three vertical ocean carbon pumps, whereas that of $A_{\mathrm{T}}$ is strongly affected by the carbonate pump, slightly affected by the BCP, and not affected by the solubility pump.

\section{Ocean carbon sequestration}

The vertical ocean carbon pumps have an important effect on the air-sea $\mathrm{CO}_{2}$ fluxes on century timescales (IPCC, 2013, Section 6.3.2.5.5). The carbon pumps contribute to carbon sequestration, which is defined as the addition of inorganic or organic carbon to a terrestrial or aquatic reservoir (i.e. to a component of the climate system other than the atmosphere), where a reservoir has the capacity to accumulate, store or release carbon (here, the definition of "carbon sequestration" and "reservoir" combines the definitions given for "sequestration", "uptake", and "reservoir" in the Glossary of IPCC, 2013, Annex III). The word "pool" is an equivalent term to "reservoir", although the definition of pool often includes the atmosphere (IPCC, 2013, Annex III). The carbon reservoirs considered here are the deep ocean waters, marine sediments, and long-lived DOC. The operational definition of carbon sequestration is study-dependent. For example in the 2013 IPCC report (section 6.5.1), "permanent" sequestration refers to timescales longer than tens of thousands of years. However because carbon is transformed by several natural cycles that operate over a range of different timescales, carbon sequestration can be of various durations: up to hundreds of millions of years in the carbonate-silicate cycle, less than one million years in the carbonate cycle, thousands or tens of thousands of years for long-lived marine DOC, and up to one thousand years when transferred into deep ocean waters.

A bibliographic search on carbon sequestration often finds papers on methods of carbon dioxide removal (CDR), which is not the same topic as natural carbon sequestration. The

latter refers to the capture and removal of $\mathrm{CO}_{2}$ from the atmosphere through naturally occurring biochemical, biological, chemical and/or physical processes, this $\mathrm{CO}_{2}$ being sequestered in natural reservoirs. Alternatively, CDR methods are a set of techniques that aim to remove $\mathrm{CO}_{2}$ directly from the atmosphere by either increasing natural sinks for carbon or using chemical or geochemical engineering approaches to remove the $\mathrm{CO}_{2}$, with the intent of reducing the atmospheric $\mathrm{CO}_{2}$ concentration. These methods may involve the ocean (e.g. iron fertilisation), land (e.g. large-scale reforestation), and technical systems (e.g. direct capture of 
$\mathrm{CO}_{2}$ from the atmosphere using engineered chemical means). Some CDR methods fall under the category of geoengineering, depending on the magnitude, scale, and impact of the particular CDR activities. This topic is reviewed in IPCC (2013, Sections 6.5.1-6.5.3).

The time horizon that has been generally used as sequestration threshold for oceanrelated studies is •100 years (e.g. Lampitt et al., 2008; Passow and Carlson, 2012; Jiao et al., 2014), however, the basis for that 100-year threshold is unclear (except a general reference to "IPCC 2007" in Lampitt et al., 2008). The apparent origin of this 100 year citation goes back to the creation of "carbon credits" under the Kyoto Protocol (signed in 1997, and entered into force in 2005). The implementation of carbon credits led to the development of the Global Warming Potential indices (GWPs), which were based on the 100-year horizon (UNFCC, 1998). These indices (which compare the amount of heat trapped in the atmosphere by a mass of a gas to the amount of heat trapped by a similar mass of $\mathrm{CO}_{2}$ ) assumed that storage for 100 years or more was permanent, and therefore equivalent to a reduction in fossil fuel emissions. However, economists have criticised the GWPs because of their weak economic rationale (e.g. Herzog et al., 2003). Despite these uncertainties, the present review will consider as a pragmatic rule, that carbon is sequestered when it is stored or accumulated in a reservoir for at least 100 years.

The deep, intermediate (i.e. permanent pycnocline) and surface waters represent 75, 16 and $9 \%$ of the ocean volume, respectively, and the deep and intermediate waters interact with the atmosphere on timescales of approximately 1000 and 10-100 years, respectively (Sarmiento and Toggweiler 1984). Hence it is below the permanent pycnocline, in deep waters (typically $>1000 \mathrm{~m}$, Section 2), that the vertical ocean carbon pumps sequester carbon. The approximate depths of carbon export and sequestration are illustrated by two horizontal dotted lines in Fig. 2, where the timescales of carbon cycling in the water column are schematically represented by three upward-pointing arrows (identified by numbers in open circles: to I) $^{2}$

The three vertical ocean carbon pumps differently influence atmospheric $\mathrm{CO}_{2}$. The solubility pump transfers carbon to the sequestration depth by downward mixing part of the atmospheric $\mathrm{CO}_{2}$ that dissolved in surface waters. The carbonate pump contributes to carbon sequestration, but because the precipitation of $\mathrm{CaCO}_{3}$ in the ocean releases $\mathrm{CO}_{2}$ to the atmosphere (see eq. 3), this pump does not lead to a decrease in the concentration of atmospheric $\mathrm{CO}_{2}$ on short time scales (i.e. <100 years; Zeebe, 2012). In the BCP, most of the organic carbon that is exported downwards is remineralised before it reaches the sequestration 
depth. Hence the effect of the $\mathrm{BCP}$ on atmospheric $\mathrm{CO}_{2}$ depends on the $e$-folding depth (also called "remineralisation length scale"), i.e. the depth at which $63 \%$ of the organic matter exported from the euphotic layer has become remineralised. The value of $63 \%$ assumes exponential remineralisation based on the Napierian constant $e=2.71828 \ldots$, i.e. [ $(1-1 / e) \times$ $100]=63 \%$. As the $e$-folding depth increases, most of the particle remineralisation occurs at greater depths in the water column (or even on the bottom), and the amount of carbon sequestered may consequently increase.

The attenuation of the downward flux of organic particles (i.e. remineralisation) is also described by exponent $b$ in the equation proposed by Martin et al. (1987):

$$
F_{s}=F_{e} \times\left(z_{s} / z_{e}\right)^{-b}
$$

where $z_{s}$ and $z_{e}$ are the depths of sequestration and export, respectively, $F_{s}$ and $F_{e}$ are the corresponding downward POC fluxes (i.e. sequestration flux and export flux, respectively), and exponent $b$ increases with increasing water-column remineralisation (in their original equation, Martin et al., 1987, considered $F$ between $z_{e}=100 \mathrm{~m}$ and any deeper depth $z$ ). Given that the $e$-folding depth $\left(z_{d}\right)$ is where $F_{s}=(1-0.63) \times F_{e}$, i.e. $F_{s}=0.37 \times F_{e}$, then $b$ and $z_{d}$ are related as follows through eq. 5 (Guidi et al. ms.):

$$
\begin{aligned}
& z_{d}=z_{e} / 0.37^{(1 / b)} \\
& b=-\log (0.37) / \log \left(z_{d} / z_{e}\right)
\end{aligned}
$$

Equations 6 and 7 functionally link the concepts of organic particle remineralisation and $e$-folding depth, which are generally not explicitly connected in the literature. Kwon et al. (2009) calculated that an increase of the $e$-folding depth by ca. $20 \mathrm{~m}$ (i.e. $2 \%$ of the upper $1000 \mathrm{~m}$ water column) could lead to a decrease in atmospheric partial pressure of $\mathrm{CO}_{2}\left(p \mathrm{CO}_{2}\right)$ of 10 to $30 \mathrm{ppm}$, i.e. 3 to $9 \%$ of the present atmospheric $p \mathrm{CO}_{2}$. This reduction in atmospheric $p \mathrm{CO}_{2}$ results from the redistribution of remineralised carbon from intermediate to bottom waters. The $e$-folding depth may be controlled by such factors as the rate of microbial consumption and remineralisation of the sinking POC, and the availability of ballast minerals as a function of atmospheric dust (Kwon et al., 2009).

The three vertical ocean carbon pumps sequester carbon in the deep waters or sediment reservoirs, in different forms: the deep ocean circulation (average timescale: ca. 1000 years), where carbon is sequestered as dissolved $\mathrm{CO}_{2}$ or DOC; sediments, where inorganic $\left(\mathrm{CaCO}_{3}\right)$ and organic carbon are sequestered for thousands of years; and the lithosphere, where carbon is sequestered for millions of years in carbonate rocks and as fossil organic carbon 
(e.g. kerogen and hydrocarbons). Sequestered organic carbon includes methane hydrate (i.e. clathrate), which is present in the upper few hundred metres of the sediments (deeper, temperature exceeds the melting point of methane hydrate). In the cold waters of the Arctic and the Antarctic, methane hydrate can occur at shallower depths (i.e. on the continental shelves and slopes <ca. 1000 m; e.g. Archer et al., 2009) than in warmer low-latitude waters. More generally, on continental shelves and slopes, carbon may be stored in shallow-water $\mathrm{CaCO}_{3}$ reefs, or delivered and stored into sediments $<1000 \mathrm{~m}$ depth. The carbon thus stored can be (but is not necessarily) returned to the atmosphere within $<100$ years. In some cases, shallow-water sediments are transported to greater depths, e.g. by turbidity currents, where their carbon can be sequestered. From a paleoceanographic perspective (e.g. Sigman and Haug, 2003), the biological pump, sensu stricto, does not include the burial of organic matter in marine sediments.

\section{DOC fractions and the microbial carbon pump}

\subsection{DOC fractions: lifetimes and production rates}

In the ocean, there is co-occurrence of different DOC fractions with different lifetimes. As reported in Jiao et al. (2014), the lifetime of a substance is defined as the time for its concentration to decrease to $1 / e$ of its initial value, i.e. $1 / e=0.37$, which assumes exponential decay. This corresponds to the concept of " $e$-folding lifetime", which differs from the related concept of "half-life" where $1 / 2$ is used instead of $1 / e$.

Here, we refer to the five DOC fractions defined by Hansell (2013, his Table 1), which are based on the $e$-folding DOC lifetimes: (1) labile DOC (LDOC; average lifetime: hours to days), (2) semi-labile DOC (SLDOC; ca. 1.5 years), (3) semi-refractory DOC (SRDOC; ca. 20 years), (4) refractory DOC (RDOC; ca. 16000 years), and (5) ultra-refractory DOC (URDOC; ca. 40000 years). Hansell (2013) calls "recalcitrant" the DOC fraction that is resistant to rapid microbial degradation and thus accumulates and is observable in the ocean (i.e. SLDOC + SRDOC + RDOC + URDOC), whereas other authors (e.g. Jiao et al., 2010) use "recalcitrant" instead of "refractory" to qualify the RDOC fraction. Here, we will use the terms "refractory" for RDOC and "recalcitrant" for SLDOC + SRDOC + RDOC + URDOC as proposed by Hansell (2013). We will also refer to DOC with average lifetime shorter or longer than 100 years, which is our reference threshold duration for carbon sequestration (see Section 3), as $\mathrm{DOC}_{<100}$ or $\mathrm{DOC}_{>100}$, respectively. 
The DOM in seawater has been considered as either discrete fractions with different lifetimes or as a single pool characterized as a continuum of reactivity (e.g. Amon and Benner, 1996; Kaiser and Benner, 2009; Hansell, 2013). On the one hand, discrete DOC fractions are operational for both field investigations where these fractions have distinctive roles in the cycling of carbon (e.g. Hansell et al., 2012), and for their incorporation in biogeochemical models (e.g. Kwon et al., 2009, De Vries et al., 2014). On the other hand, a very promising approach to investigate the various DOC components and their production rates is ultra-high resolution mass spectrometry (Fourier transform ion cyclotron resonance mass spectrometry, FT-ICR-MS), which provides unprecedented insight into the composition of DOM (e.g. Hertkorn et al., 2006; Osterholz et al., 2014; Romano et al., 2014). Aspects relevant to RDOC and the MCP are reviewed by Jiao et al. (2014). Such detailed chemical and physiological information cannot be readily included in biogeochemical models, similarly to the wealth of taxonomic information that must be "distilled" into plankton functional types to be used in biogeochemical models (e.g. Le Quéré et al., 2005). However, once assimilated into biogeochemical models, these new results on the various DOC components could improve the current views of the roles of discrete components of the DOC pool in the cycling of and transport of carbon in food webs and biogeochemical cycles.

Hansell (2013, his Table 1) also reported the World Ocean inventory and annual carbon production rate $\left(\mathrm{P}_{\mathrm{DOC}}\right)$ for the five $\mathrm{DOC}$ fractions. The shortest-lived fractions have the highest production rates, and conversely, the longest-lived fractions have the lowest production rates (Table 3, Fig. 4). The $\mathrm{P}_{\mathrm{DOC}}$ value for URDOC deviated from the general relationship between $\mathrm{P}_{\mathrm{DOC}}$ and DOC lifetime (Table 3), perhaps reflecting the fact this DOC fraction differs from RDOC (which is mostly from marine food webs) as it includes thermogenic black carbon and also possibly DOC of hydrothermal origin (Dittmar and Paeng, 2009; McCarthy et al., 2011; Hansell, 2013). We used the following ordinary least square regression equation (i.e. predictive form of Model II regression) from Jiao et al. (2014), which is based on the values of $\mathrm{P}_{\mathrm{DOC}}$ and average lifetime for LDOC, SLDOC, SRDOC and RDOC in Table 3:

$$
\log _{10}\left(\mathrm{P}_{\mathrm{DOC}}\right)=0.29-0.40 \log _{10}(\text { average lifetime })
$$

with $\mathrm{r}^{2}=0.96$ (solid line in Fig. $4 ; \mathrm{r}=-0.98, \mathrm{~N}=4, \mathrm{P}<0.05$ ). This shows that although the average lifetimes of LDOC, SLDOC, SRDOC and RDOC are discrete values, these are part of a continuum. We assumed that the corresponding $\mathrm{P}_{\mathrm{DOC}}$ also formed a continuum. 
Because the carbon present in DOC with an average lifetime $>100$ years $\left(\mathrm{DOC}_{>100}\right)$ is considered to be sequestered, we calculated, using the values in Table 3, the production rate of DOC $>100\left(\mathrm{P}_{\mathrm{DOC}>100}\right)$. The sum of $\mathrm{P}_{\mathrm{DOC}}$ values in Hansell $(2013$, his Table 1) and in our Table 3 is $28.8 \mathrm{Pg} \mathrm{C}_{\text {year }}{ }^{-1}$, and our goal was to partition this production rate of total DOC between the production rates of DOC with an average lifetime $<100$ years $\left(\mathrm{P}_{\mathrm{DOC}<100}\right)$ and $\mathrm{P}_{\mathrm{DOC}>100}$. In order to do so, we did proceed in five steps. Firstly, we divided the range of average lifetimes (from $0.001=10^{-3}$ to $16000=10^{4.2}$ years, total range of $10^{7.2}$ years) by three $(7.2 \div 3=2.4$ logarithmic units), to obtain four classes that would extend to below and above the minimum and maximum average lifetimes, respectively. Secondly, we divided the range of lifetimes between $10^{-(3+1.2)}$ and $10^{(4.2+1.2)}$ years, i.e. $10^{-4.2}$ and $10^{5.4}$ years, into four classes of 2.4 logarithmic units each (third column in Table 3). Thirdly, we assumed the following: (i) the limits of the four lifetime classes defined the ranges of lifetimes for the corresponding DOC fractions, e.g. the range of lifetimes of SRDOC (average lifetime of $10^{1.3}$ years) was set to $10^{0.6}$ to $10^{3}$ years (i.e. the limits of our third lifetime class, third column in Table 3); (ii) the $\mathrm{P}_{\text {DOC }}$ values in Table 1 of Hansell (2013) corresponded to the successive ranges of lifetimes, e.g. for SRDOC, $\mathrm{P}_{\mathrm{DOC}}=0.34 \mathrm{PgC}$ year ${ }^{-1}$ corresponded to the range of lifetimes $10^{0.6}$ to $10^{3}$ years (third and fifth columns in Table 3); (iii) the $\mathrm{P}_{\mathrm{DOC}}$ values corresponding to the four ranges of lifetimes were additive because of the way these values were originally computed by Hansell et al. (2012, their eq. 1), i.e. the PDOC values for LDOC, SLDOC, SRDOC and RDOC in the fifth column of Table 3 could be added together to obtain total $\mathrm{P}_{\mathrm{DOC}}=$ 28.8 $\mathrm{Pg} \mathrm{C}_{\text {year }}{ }^{-1}$. Fourthly, because the $\mathrm{P}_{\mathrm{DOC}}$ values were assumed to be additive, we could fractionate the value within any range of lifetimes, e.g. in order to obtain $\mathrm{P}_{\mathrm{DOC}>100}$, we fractionated (fifth column of Table 3) $\mathrm{P}_{\mathrm{DOC}}$ in the lifetime range $10^{0.6}$ to $10^{3}$ years (SRDOC) into $\mathrm{P}_{\mathrm{DOC}<100}$ and $\mathrm{P}_{\mathrm{DOC}>100}$, and added the resulting $\mathrm{P}_{\mathrm{DOC}>100}$ fraction to $\mathrm{P}_{\mathrm{DOC}}$ in the lifetime range $10^{3}$ to $10^{5.4}$ years (RDOC, whose average lifetime is $>100$ years). Fifthly, based on the above assumptions (and as described in Table 3), we calculated, the values of $\mathrm{P}_{\mathrm{DOC}<100}$ and $P_{\text {DOC }>100}$ (horizontal double-arrowed dotted lines on both sides of the vertical dotted line in Fig. 4, and bottom two rows of Table 3 ). The estimate of $\mathrm{P}_{\mathrm{DOC}>100}$ was $0.18 \mathrm{Pg} \mathrm{C}_{\text {year }}{ }^{-1}$ (i.e. last row of Table 3).

Here we examine whether the estimated rate of total $\mathrm{P}_{\mathrm{DOC}}$ of $28.8 \mathrm{Pg} \mathrm{C}$ year ${ }^{-1}$ (Hansell 2013, his Table 1, and our Table 3) is consistent with both the estimates of PP ca. $50 \mathrm{Pg} \mathrm{C}$ year $^{-1}$ in the World Ocean (e.g. Carr et al., 2006) and the reports that most organic carbon from PP is respired by the marine food web (e.g. Lampitt et al., 2008). Assuming that 
the percentage of extracellular release by phytoplankton (PER) is $20 \%$ of PP (Marañón et al., 2004), the dissolved and particulate fractions of $\mathrm{PP}$ would be $\mathrm{PP}_{\mathrm{DOC}}=10$ and $\mathrm{PP}_{\mathrm{POC}}=$ $40 \mathrm{Pg} \mathrm{C}$ year ${ }^{-1}$, respectively. Hence, a total $\mathrm{P}_{\mathrm{DOC}} \approx 30 \mathrm{Pg} \mathrm{C}$ year $^{-1}$ would require that the food web release ca. $20 \mathrm{Pg} \mathrm{C}$ year ${ }^{-}$(i.e. $\mathrm{P}_{\mathrm{DOC}}$ ), corresponding to ca. $50 \%$ of $\mathrm{PP}_{\mathrm{POC}}$. Bacteria derive a large fraction of their DOC via heterotrophic food web transformations of $\mathrm{PP}_{\mathrm{POC}}$ (e.g. Fasham et al., 1999; Nagata, 2000). The requirement that $\mathrm{P}_{\mathrm{DOC}}=0.5 \mathrm{PP}_{\mathrm{POC}}$ is consistent with the values of heterotrophic $\mathrm{P}_{\mathrm{DOC}}$ calculated with the model of Legendre and Rivkin (2008, their Table 6) for the herbivorous, multivorous and microbial food webs, which ranged from 0.30 to 0.46 of PP, i.e. 0.4 to 0.6 of $\mathrm{PP}_{\mathrm{POC}}$ given that $\mathrm{PER}=0.2$ in that model. The remaining 50\% of $\mathrm{PP}_{\mathrm{POC}}$ could be exported to depth or processed by the food-web in the upper water column, where most of it would be respired back to $\mathrm{CO}_{2}$. Similarly, the fraction of $\mathrm{P}_{\mathrm{DOC}}$ with a lifetime $<1$ year $\left(>90 \%\right.$ of total $\mathrm{P}_{\mathrm{DOC}}$, Fig. 4 ) would be respired within the year. Although only an estimate, the total $\mathrm{P}_{\mathrm{DOC}} \approx 30 \mathrm{PgC}$ year $^{-1}$ is consistent with both $\mathrm{PP} \approx$ $50 \mathrm{Pg} \mathrm{C}$ year $^{-1}$ and respiration by the food web of most of the organic carbon derived from PP (Fig. 5).

\subsection{The microbial carbon pump: microbiological concept and biogeochemical units}

Jiao and collaborators (Jiao et al., 2010; Jiao and Azam, 2011; Jiao et al., 2011) proposed that the production of the longer-lived DOC fractions (i.e. SRDOC, RDOC, and URDOC) largely resulted from the activity of marine pelagic microbes (i.e. unicellular autotrophic and heterotrophic planktonic organisms and viruses; e.g. Legendre and Rivkin, 2008), and thus called the suite of marine microbial processes that led to the production of these DOC fractions "microbial carbon pump". These authors suggested that heterotrophic microbes and viruses, in addition to being major agents of organic carbon remineralization in the ocean, could also contribute to the production of long-lived DOC and thus increase the lifetime of some organic carbon.

Although the MCP concept was not defined initially in the same terms, or expressed in the same units as the three vertical ocean carbon pumps (Section 2), the MCP has the same fundamental characteristic as the three other carbon pumps in that it maintains a gradient in concentration of carbon compounds. For the three vertical ocean carbon pumps, the gradient is between surface- and deep-water $C_{\mathrm{T}}$ (Section 2), whereas for the MCP, the gradient is between $\mathrm{DOC}_{<100}$ and $\mathrm{DOC}_{>100}$, whose inventories are 14 and $636 \mathrm{Pg} \mathrm{C}$ in the World Ocean (Table 3). The $\mathrm{DOC}_{<100}$ and $\mathrm{DOC}_{>100}$ fractions correspond to a wide variety of organic compounds (see Section 4.1), but these compounds share the common characteristic of having 
average lifetimes either $<100$ or $>100$ years. The huge $\mathrm{DOC}_{<100}$ to $\mathrm{DOC}_{>100}$ gradient is maintained against the continuous degradation of $\mathrm{DOC}_{>100}$ (mostly by photochemical transformation, Section 6.2). The gradient also exists in the surface layer (where most DOC is produced), e.g. RDOC accounts for ca. $65 \%$ of the ca. $66-67 \mu \mathrm{mol} \mathrm{kg}^{-1}$ of recalcitrant DOC (i.e. SLDOC+SRDOC+RDOC) that are found in surface waters of the Western Sargasso Sea and the Southern Ross Sea (Hansell, 2013, his Fig. 5). The MCP is represented in Fig. 2 to the right of the three vertical ocean carbon pumps, where rightward-pointing arrow the numbers in full or open circles in this section refer to arrows in Fig. 2), from "DOC + POC" to "SRDOC $+\mathrm{RDOC} \geq 100$ years", illustrates the idea that $\mathrm{DOC}_{>100}$ is derived from $\mathrm{DOC}+$ POC, and the vertical spread of the "RDOC + SRDOC $\geq 100$ years" box illustrates the idea that the vertical distribution of the carbon sequestered by the MCP is depth-independent. The carbon processes involved in the four pumps, both in surface waters and below, are listed on the right-hand side of Fig. 2.

One of the mechanisms invoked for the production of RDOC, i.e. the successive - and perhaps repetitive - processing of DOC by the microbial food web that transforms some of the LDOC and SLDOC into RDOC (Jiao et al., 2010, 2011), is associated with remineralisation (i.e. heterotrophic respiration) of most of the organic carbon processed by microorganisms. Hence the resulting transformation of carbon into longer-lived DOC by this MCP mechanism causes the release of respiratory $\mathrm{CO}_{2}$ in the water, which not only increases $C_{\mathrm{T}}$ but is also accompanied by a slight decrease in $A_{\mathrm{T}}$ as explained for the BCP in Section 2. Some other mechanisms invoked for the production of RDOC are not necessarily associated with heterotrophic respiration, e.g. direct exudation of RDOC by phytoplankton or RDOC resulting from viral lysis (Jiao and Azam, 2011; their Fig. 2). The combined effects of the MCP on $C_{\mathrm{T}}$ and $A_{\mathrm{T}}$ are illustrated in Fig. 3.

To allow direct comparisons with the three vertical ocean carbon pumps, here we normalise the physical dimensions of the MCP to the same dimensions $\left[\mathrm{ML}^{-2} \mathrm{~T}^{-1}\right]$ (Section 2$)$. Because the MCP integrates a suite of marine microbial processes leading to the production of the longer-lived DOC fractions, here we define the magnitude of the $\mathrm{MCP}$ as the rate of production of longer-lived DOC, i.e. $\mathrm{P}_{\mathrm{DOC}>100}$. The dimensions are $\left[\mathrm{ML}^{-2} \mathrm{~T}^{-1}\right]$ and the units $\mathrm{g} \mathrm{C} \mathrm{m}^{-2}$ year $^{-1}$ or mol C m${ }^{-2}$ year ${ }^{-1}$, or for the whole ocean, $\mathrm{Pg} \mathrm{C}_{\text {year }}{ }^{-1}$ or Pmol C year ${ }^{-1}$, identical to the dimensions and units of the three vertical ocean carbon pumps.

The lifetimes of the different DOC fractions are related to the depths where these occur. This is illustrated in Fig. 6 of Hansell (2013) where bulk concentrations of DOC on a 
meridional section in the North Atlantic (from 0 to $60^{\circ} \mathrm{N}$ ) to the depth of $2000 \mathrm{~m}$ are interpreted in terms of presence/absence of SLDOC, SRDOC and RDOC, i.e. SLDOC is restricted to surface waters, SRDOC occurs between the surface and $\sim 400-500 \mathrm{~m}$ in equatorial and tropical waters (and $2000 \mathrm{~m}$ at latitudes higher than $45^{\circ} \mathrm{N}$ ), and RDOC occurs over the whole water column at all latitudes. As a consequence, the concentration of total DOC is higher in surface waters, where all DOC fractions are present, than below, where only the longer-lived DOC is thought to occur (Fig. 1). Below $\sim 100 \mathrm{~m}$, there is production of DOC by food-web activities, but the concentrations of LDOC and SLDOC (and SRDOC at low latitudes) are generally low because this DOC is recycled (i.e. consumed, and partly repackaged into POC or metabolised to $\mathrm{CO}_{2}$ and longer-lived DOC) more rapidly than the ca. 1000-year mixing timescale of the ocean, and consequently does not accumulate. In contrast, micromolar concentrations of longer-lived DOC fractions occur in significant amounts at all depths in the ocean, with latitudinal variations (Carlson et al., 2010; Jiao et al., 2010; Jiao and Azam, 2011; Jiao et al., 2011; Hansell, 2013), and this indicates that the longer-lived DOC fractions (i.e. $\mathrm{DOC}_{>100}$ ) are redistributed vertically by various physical and biological mechanisms (see Section 6.3). Below $1000 \mathrm{~m}$, the concentrations of DOC in the ocean are about two orders of magnitude smaller than the concentrations of $C_{\mathrm{T}}$ (Fig. 1).

Similar to the three vertical ocean carbon pumps, the MCP contributes to the sequestration of atmospheric carbon in the ocean, albeit by a very different mechanism Whereas the three vertical ocean carbon pumps transfer carbon from the ocean surface to the ocean interior, the MCP contributes to carbon sequestration through the biochemical transfer of carbon from organic compounds with a lifetime $<100$ years to DOC fractions with a lifetime $>100$ years, i.e. URDOC, RDOC, and part of SRDOC. Although it has been suggested that refractory DOC could have timescales of several months to a year (e.g. Benner and Herndl, 2011), here sequestration under the form of refractory DOC is restricted to DOC with lifetimes of $\geq 100$ years (see Section 3). Thus application of the MCP concept is limited to the suite of processes that transfer carbon to $\mathrm{DOC}_{>100}$.

The proposal that long-lived DOC could sequester carbon in the ocean, predates the MCP concept by at least two decades. For example, Legendre and Le Fèvre $(1991,1995)$ proposed that "long-lived DOC could chemically retain (i.e. sequester) carbon in the surface layer, for periods of interest to global change (i.e. 100s years)" and "carbon bound into refractory dissolved organic matter is chemically sequestered in the upper ocean", in the two papers respectively. Similarly, Legendre and Rassoulzadegan (1996) stated that: "sequestered 
biogenic carbon may take various forms, among which [...] refractory dissolved organic matter". Likewise, Ogawa and Tanoue (2003) wrote "[refractory DOC] plays a potential role for the sequestration of fixed carbon in the ocean, suggesting its importance in understanding of the mechanism of global warming". However, the MCP concept developed a broader framework where different microbes had key roles in producing $\mathrm{DOC}_{>100}$. The microbial food web has sometimes incorrectly been called MCP in the recent literature, i.e. the MCP certainly involves the microbial food web, but the latter has other important environmental and food-web effects than producing RDOC.

In Sections 2 and 4.2, the expression "carbon pump" was explicitly defined to address the transfer of carbon specifically toward deep waters or long-lived DOC against a gradient (concentration or chemical lifetime). This is done to keep the concept of carbon pumps operational. Otherwise, any carbon transfer (e.g. transfer of carbon to a depth or to a DOC fraction where the carbon is not sequestered) could be considered to be a pump. This could compromise our current understanding of the ocean carbon pump concept because the expressions "carbon transfer" and "carbon pump" would then be synonymous.

\section{Comparison of the microbial and vertical ocean carbon pumps}

\subsection{The microbial and solubility carbon pumps}

The solubility pump sequesters carbon by transferring $C_{\mathrm{T}}$ downwards, the first step being the dissolution of atmospheric $\mathrm{CO}_{2}$ in the upper ocean, followed by deep mixing of the $\mathrm{CO}_{2}$-rich water (Section 3). As the concentration of atmospheric $\mathrm{CO}_{2}$ increases, more $\mathrm{CO}_{2}$ dissolves in surface-ocean waters, leading to increasing concentration of $\mathrm{H}^{+}$in seawater (eq. 2), thus decreasing the $\mathrm{pH}$. This is called ocean acidification. This change in the ocean carbonate chemistry may have large effects on marine organisms and biogeochemical cycles (e.g. Doney et al., 2009). In contrast, in the MCP, marine microbes and their food web channel organic carbon into the $\mathrm{DOC}_{>100}$ reservoir, where carbon is sequestered (Jiao et al., 2010; Hansell, 2013).

According to Jiao et al. (2010), the storage of carbon into RDOC (i.e. the MCP) does not appreciably alter the buffering capacity of seawater and has no known negative effects on marine organisms, which would be a major difference from the solubility pump. However, the successive processing of DOC by the microbial food web that transforms some of the LDOC and SLDOC into RDOC (Jiao et al., 2010, 2011) is accompanied by heterotrophic respiration, and this heterotrophic respiration is accompanied by a small decrease in $A_{\mathrm{T}}$ (Section 4.2, and 
Fig. 3). This slightly decreases the buffering capacity of seawater. Hence the MCP (as well as the BCP, Section 2) may have small effects on $A_{\mathrm{T}}$.

\subsection{The microbial and biological carbon pumps}

Here we compare the sequestrations mechanisms of the BPC and the MCP, their spatiotemporal variability, and their magnitudes in the World Ocean. The sequestrations mechanisms of the BPC and the MCP are distinct (Sections 3 and 4.2).

The BCP sequesters carbon by transferring organic matter into deep waters, i.e. the vertical distribution of the carbon sequestered through the BCP is depth dependent. The BCP leads to the sequestration into different reservoirs below ca. $1000 \mathrm{~m}$ of carbon supplied by sinking or vertically transported POC and vertically mixed DOC that is not associated with the MCP (i.e. that has not been transformed into long-lived DOC by the MCP). Some studies consider that SLDOC and SRDOC constitute the dissolved phase of the BCP (e.g. Hansell, 2013). However, most of the SLDOC and SRDOC that is exported from the surface ocean is remineralised to $\mathrm{CO}_{2}$ above the depth of sequestration and thus does not contribute to the BCP. Exceptions are SRDOC export at sites of deep-water formation, e.g. in the North Atlantic Ocean (see Fig. 6 in Hansell, 2013). The carbon sequestered by the BCP is ultimately stored in different forms, e.g. $\mathrm{CO}_{2}$, SRDOC, RDOC, URDOC, carbonate rocks and fossil organic carbon (Section 3).

In contrast, the MCP sequesters carbon by biochemically transforming organic compounds to non-bioavailable carbon forms, i.e. by transferring carbon to the $\mathrm{DOC}_{>100}$ reservoir. This reservoir exists at all depths in the ocean (Section 4.2), and thus the vertical distribution of the carbon sequestered by the MCP is depth-independent, i.e. $\mathrm{DOC}_{>100}$ is redistributed over the whole water column by various mechanisms examined in Section 6.3. Moreover, even if the depth redistribution mechanisms of $\mathrm{DOC}_{>100}$ overlap with the vertical transfer of carbon by the BCP, the two ocean carbon pumps are distinct. Carbon sequestration by the MCP is a consequence of the production of $\mathrm{DOC}_{>100}$ and is independent of its vertical redistribution. In cases when carbon is sequestered at depth by the BCP, its further deep-water microbial transformation into $\mathrm{DOC}_{>100}$ would not change the initial assignment of this carbon to the BCP. Similarly, when carbon is sequestered by the MCP above $1000 \mathrm{~m}$, its further vertical transport below $1000 \mathrm{~m}$ would not change the initial assignment of this carbon to the MCP. This operational "first-time-sequestration" criterion prevents organic carbon fluxes from being assigned to both the $\mathrm{BCP}$ and the $\mathrm{MCP}$, which is an important requirement for comparing or using the two ocean carbon pumps in models. 
Very little is known about the spatio-temporal variability of the MCP. Although quantitative estimates are lacking, Jiao et al. (2010) proposed that the relative importance of the MCP and the BCP would vary both spatially and seasonally. These authors predicted that, in eutrophic waters, where primary production is high, the magnitude of carbon sequestration mediated by POC export via the BCP would probably exceed that mediated by the MCP, whereas in oligotrophic waters, the MCP would be more important than the BCP. They concluded that the relative importance of the MCP versus the export of POM by the BCP was expected to change if a system shifted from high to low productivity.

Here, we compare the magnitudes of the BCP and the MCP in the World Ocean. Based on data from deep sediment traps, Honjo et al. (2008) estimated that the ocean-wide downward flux of POC at $2000 \mathrm{~m}$ was $0.43 \mathrm{Pg} \mathrm{C}_{\mathrm{gear}}{ }^{-1}$. Other estimates for the POC flux at $2000 \mathrm{~m}$ were $0.31 \mathrm{Pg} \mathrm{C}$ year $^{-1}$ (Lutz et al., 2007; estimate at $2500 \mathrm{~m}$ ), 0.66 $\mathrm{Pg} \mathrm{C}_{\text {year }}{ }^{-1}$ (Henson et al., 2012), and $0.33 \mathrm{Pg} \mathrm{C}_{\text {year }}{ }^{-1}$ (Guidi et al., ms.) The corresponding estimates at $1000 \mathrm{~m}$, using the average value $b=0.86$ for the North Pacific Ocean (Martin et al., 1987), would be $(1000 / 2000)^{-0.86}=1.815$ or $(1000 / 2500)^{-0.86}=2.199$ times higher than at 2000 or $2500 \mathrm{~m}$, respectively (eq. 5). Hence the reported fluxes at 2000 or $2500 \mathrm{~m}$ of $0.43,0.31,0.66$ and $0.33 \mathrm{Pg} \mathrm{C}_{\text {year }}{ }^{-1}$ would be $0.78,0.68,1.20$ and $0.60 \mathrm{Pg} \mathrm{C}_{\mathrm{gear}}{ }^{-1}$ when scaled to $1000 \mathrm{~m}$. Based on these fluxes, the magnitude of the BCP could be between 0.3 and $0.7 \mathrm{Pg} \mathrm{C}_{\text {year }}{ }^{-1}$ at $2000 \mathrm{~m}$ and 0.6 and 1.2 Pg C year ${ }^{-1}$ at $1000 \mathrm{~m}$. This does not include a small BCP-mediated flux of DOC below $1000 \mathrm{~m}$. Assuming that PP $=50 \mathrm{Pg} \mathrm{C}_{\text {year }}{ }^{-1}, \mathrm{BCP}$ at 2000 and $1000 \mathrm{~m}$ would represent $0.6-1.3$ and $1.2-2.4 \%$ of PP, respectively.

In contrast, there are very few estimates of the magnitude of the MCP (i.e. $\mathrm{P}_{\mathrm{DOC}>100}$ ). Brophy and Carlson (1989) estimated the ocean-wide production of refractory DOC to 0.5$0.6 \mathrm{Pg} \mathrm{C}$ year $^{-1}$. However, this estimate is incorrect because these authors had interpreted the production of high-molecular weight DOC as bacterial conversion of labile into refractory material. Indeed, other studies have shown that the high molecular weight DOC was more labile and bioreactive than low molecular weight DOC (e.g. Amon and Benner, 1996). Benner and Herndl (2011) proposed that bacteria produced 0.008-0.023 Pg C year ${ }^{-1}$ of DOC that was refractory on time scales of several months to a year, indicating that their estimate was likely to be conservative. Jiao et al. (2014) combined the production rates of SRDOC, RDOC and URDOC (Table 3) to obtain an estimate of $\mathrm{P}_{\mathrm{DOC}>100}$ of $0.38 \mathrm{Pg} \mathrm{C}_{\text {year }}{ }^{-1}$. However, this is a maximum estimate because part of SRDOC has an average lifetime $<100$ years. In Section 4.1, our approach was to divide the production of SRDOC into two fractions, i.e. $\mathrm{P}_{\mathrm{DOC}<100}$ and 
$\mathrm{P}_{\mathrm{DOC}>100}$, and to use the SRDOC $\mathrm{P}_{\mathrm{DOC}>100}$ fraction to estimate combined $\mathrm{P}_{\mathrm{DOC}>100}$ in SRDOC and RDOC, whose value was $0.18 \mathrm{Pg} \mathrm{C}_{\text {year }}{ }^{-1}$ (fifth row of Table 3 ). This is, to our knowledge, the first quantitative estimate for the magnitude of the MCP as defined above, which must be taken with caution considering the uncertainties in our assumptions and approach. Assuming that $\mathrm{PP}=50 \mathrm{Pg} \mathrm{C}$ year $^{-1}$, our estimate of the magnitude of the MCP would represent $0.4 \%$ of PP.

In an ongoing study, DeVries et al. (2014) predicted the magnitude of the BCP and the MCP in the contemporary ocean from the assimilation of nutrient and DOC observations into a global physical/biogeochemical ocean model. The model includes SLDOC and RDOC, whose production rates and lifetimes are adjusted to match the DOC observations in the ocean; the RDOC pool ends up having a lifetime of about 9000 years. Preliminary results for the BCP were a POC flux of $1.16 \pm 0.03 \mathrm{Pg} \mathrm{C}_{\text {year }}{ }^{-1}$ at $1000 \mathrm{~m}$ and $0.40 \pm 0.02 \mathrm{Pg} \mathrm{C}_{\text {year }}{ }^{-1}$ at $2000 \mathrm{~m}$, and for the MCP, a production rate of RDOC of $0.069 \pm 0.004 \mathrm{Pg} \mathrm{C}_{\mathrm{year}}{ }^{-1}$. Given the very different approaches used in this model and above to estimate the magnitude of the MCP, the values in our and DeVries's studies (i.e. 0.18 and $0.07 \mathrm{Pg} \mathrm{C}_{\mathrm{Cear}}{ }^{-1}$, respectively) are quite consistent.

\section{Review of reports of refractory dissolved organic carbon processes in the ocean}

The MCP proposal has prompted the publication of a number of syntheses and complementary papers on RDOC and the MCP (e.g. the 10 papers in Chapter 2 of Jiao et al., 2011; Jiao et al., 2014). Here, we briefly review and assess the MCP-relevant DOC information. The terms "refractory" or "recalcitrant" DOC or DOM (RDOC or RDOM) reported in some publications do not always correspond to the definition of RDOC given in Section 2 and used here, and may also often include URDOC and part of SRDOC.

\subsection{Production of refractory dissolved organic carbon in the ocean}

The origin of RDOC in the ocean, and the processes and mechanisms of its production, utilization and degradation are largely unknown (Jiao et al., 2010; Azam and Jiao, 2011; Eichinger at al., 2011; Hansell, 2013), and studies elucidating these processes are required. Despite the paucity of information, several processes and mechanisms of RDOC production have been proposed in the literature. We summarise them considering successively the abiotic and the biotic processes.

The abiotic processes that influence $\mathrm{P}_{\mathrm{DOC}}$ and the MCP include (Carlson et al, 2013): the adsorption of LDOC and SLDOC onto colloidal material and the modification of chemical 
bond structure of LDOC and SLDOC by exposure to ultraviolet light (UV) (Keil and Kirchman, 1994; Naganuma et al., 1995); and the formation of compounds such as melanoidins via condensation reactions. These processes also include the alteration of biomolecules by heat (Dittmar and Paeng, 2009). Ultra-refractory DOC (URDOC) is likely to be primarily thermogenic, and includes thermogenic black carbon (Hansell, 2013).

Published studies on marine DOC and the MCP generally refer to the role of heterotrophic bacteria in the uptake and transformation of DOC, without considering the possible role of Archaea, which may be as important but is poorly known (e.g. Jiao and Azam, 2011). Here the term "bacteria" will refer to both heterotrophic Bacteria and Archaea.

Among the abiotic processes, the role of solar radiation, and especially UV, is still controversial and incompletely understood. Indeed, UV irradiation has been invoked as a factor that can promote both the production of RDOC (Kieber et al., 1997; Benner and Biddanda, 1998; Hansell, 2013) and its removal by photodegradation in the surface ocean (Section 6.2). UV radiation can convert more labile DOC (i.e. simple compounds and byproducts of photosynthesis) to recalcitrant forms of DOC (Tranvik and Bertilsson, 2001; Hansell 2013).

Autotrophic and heterotrophic microbes are possible sources of RDOC. The biotic processes that may lead to RDOC include: the direct exudation of DOC from phytoplankton; the production of liposome-like colloids via microzooplankton grazing; the release of metabolites by microbes; the preferential removal of specific sugars and amino acids by bacteria (Carlson et al., 2011); the viral lysis of picocyanobacteria, autotrophic eukaryotic plankton, and bacteria in the euphotic zone (Jiao et al., 2010; Weinbauer et al., 2011); programmed cell death (i.e. apoptosis) of a high-salinity micro-alga, and use of the resulting DOC by an archaeon (Orellana et al., 2013); the generation of microenvironmental conditions (e.g. chemical gradients and oxygen depletion) around microbial cells (Jiao et al., 2010); and the possible de novo production of RDOC by metabolic activities of phytoplankton or bacteria. The latter process is mechanistically distinct from bacteria successively transforming labile into refractory organic carbon (Jiao and Azam, 2011).

Phytoplankton may directly exude RDOC (Carlson et al., 2011; Jiao and Azam, 2011). However, the most frequently cited mechanism related to phytoplankton exudation is bacterial transformation into RDOC of some more labile DOC exuded by phytoplankton and other organisms (Benner and Herndl, 2011; Jiao and Azam, 2011; Kattner et al., 2011). 
Bacteria consume most of the DOC exuded by phytoplankton and other organisms, and part of the DOC that is not respired is transformed into RDOC (Benner and Herndl, 2011). Eichinger et al. (2011) proposed that bacterial RDOC production may occur as a stress response when LDOC availability is low, based on a model that reproduced the results of a 10-day laboratory experiment (Eichinger et al., 2009). In addition, bacteria produce directly exopolymers and capsular material, either as part of their normal life strategy or under stress conditions, e.g. nutrient limitation when they take up much more carbon than needed (Stoderegger and Herndl, 1998, 1999). Also, bacteria hydrolyze POC in the euphotic zone or during its downward transit, using their ectoenzymes, and consume most of the resulting DOC; some by-products of this hydrolytic activity could be resistant to further utilization by microbes, i.e. RDOC (Jiao et al., 2010).

Grazing and egestion by protists have been cited as possibly contributing to the production of RDOC (Jiao et al. 2010). However studies involving ciliates has suggested that their presence did not increase the production of RDOC by bacteria (Gruber et al., 2006; Benner and Herndl, 2011). A review by Nagata (2008) concluded that it is uncertain if the composition of the bacterial community and the structure of the microbial food web control the composition and turnover of oceanic DOC (hence carbon sequestration by the MCP) through the release of specific cellular components by protist grazing and viral lysis. Hence, production of RDOC following grazing and excretion by protists is highly uncertain, and is likely of secondary importance relative to the other microbial food web processes.

Overall, it is thought that the successive processing of DOC by the microbial food web transforms some of the LDOC and SLDOC into RDOC (Jiao et al., 2010, 2011). The possible pathways of RDOC generation have been summarised by Jiao and Azam (2011, their Fig. 2). (i) Active exudation from living microbial cells, and release from such cells by viral lysis (i.e. a portion of the DOC produced by viral lysis could be RDOC) or grazing. (ii) POC degradation, where ectoenzymes released by microorganisms convert POC to DOC at rates that often exceed microbial uptake of the DOC, and some by-products of this hydrolytic activity could be resistant to further utilization by microbes (either free-living or attached to POC), thus being transformed into RDOC. (iii) Formation from residual DOC, i.e. the part of bulk DOC that could remain/become RDOC after microbial processing. However, most of these mechanisms are still largely hypothetical, and the evidence for biotic long-lived DOC production is most compelling for the direct excretion by heterotrophic bacteria of compounds that are recalcitrant on timescales of several months to a year (Benner and Herndl, 2011). 


\subsection{Removal of refractory dissolved organic carbon in the ocean}

Little is known about the mechanisms that remove RDOC from the ocean. For example, it is unclear whether the removal of longer-lived DOC is mainly by photodegradation in surface waters, processes that occur in deep waters, or interactions with the Earth's crust (Hansell, 2013). In deep waters, deep-sea microorganisms may have the ability to degrade and utilize some of the DOC that was refractory in the upper water column (Carlson et al., 2011; Kujawinski, 2011). In addition, DOC may be removed from deep waters through adsorption onto sinking particles and aggregation by formation into organic gels that lead to particle formation followed by deposition in sediments (Druffel et al., 1992), and by entrainment in the hydrothermal circulation within Earth's crust (Hansell et al., 2009). Transformation or removal of RDOC below $1000 \mathrm{~m}$ depth does not change the amount of carbon that is sequestered (Section 6.3).

Organic and inorganic carbon contained in deep waters is returned to the upper ocean over the timescales of ocean ventilation, i.e. centuries to ca. 1000's of years. Some of the RDOC in deep waters that are upwelled or otherwise transported to the upper water column may be removed in surface waters. The only mechanism suggested in the literature for surface removal of deep-water RDOC is UV irradiation of RDOC (Mopper et al., 1991). The terms,protodegradation, photolysis and photooxidation are often used interchangeably in the marine DOC literature. The definitions of these terms as recommended by the International Union of Pure and Applied Chemistry can be found in Verhoeven (1996). Here we will use the general term photodegradation, which is defined as the photochemical transformation of a molecule into lower molecular weight fragments, usually in an oxidation process. Concerning the photodegradation of DOC in the ocean, once RDOC is exposed to surface UV radiation, it may be altered and may become available for uptake and remineralisation by bacteria (Mopper et al., 1991, Moran and Zepp, 1997; Benner and Biddanda, 1998).

Experimental irradiation of deep water incubated under natural sunlight has led to the photoproduction of bioavailable substrates from deep-water DOC (Benner and Biddanda, 1998), which was presumably RDOC. Similarly, there was relatively rapid photodegradation of dissolved black carbon (DBC) from deep waters put under a solar simulator, indicating a photochemical half-life for oceanic DBC $<800$ years (Stubbins et al., 2012). This experiment suggests that photodegradation is the primary sink for oceanic DBC, and the apparent survival of DBC in the oceans for millennia is facilitated not by its inherent inertness but by the rate at which it is cycled through surface waters by the 1000 -year timescale ocean circulation. 


\subsection{Vertical redistribution of the longer-lived DOC fractions}

The occurrence of the longer-lived DOC fractions at all depths indicates that these are vertically redistributed (Section 4.2). The abiotic processes that transfer to depth the RDOC that is produced in surface waters include: ocean circulation (Hansell, 2013), convective mixing including deep-water formation (Hansell et al., 2009), possible scavenging by sinking particles (i.e. adsorption onto particles; Jiao et al., 2010), and possible formation of aggregates combining non-sinking RDOC with transparent exopolymer particles and marine snow (Jiao et al., 2010).

Organic compounds resistant to microbial degradation at one depth horizon may serve as substrates for populations of heterotrophic microbes deeper (e.g. after export of euphoticzone DOC to depths >500 m; Carlson et al., 2011). Although RDOC may be transported from surface to more than ca. $1000 \mathrm{~m}$ depth and consumed or remineralised to $\mathrm{CO}_{2}$ there, this carbon is still sequestered because sequestration below ca. $1000 \mathrm{~m}$ depth is independent of form or oxidation state.

\section{Potential effects of climate change on the microbial carbon pump}

The potential effects of climate change on the BCP were reviewed by Passow and Carlson (2012) and Turner (2014), and will therefore not be addressed here. The authors considered that the sequestration flux depends upon the input rates of allochthonous nutrients to the ocean (i.e. aeolian or fluvial inputs, or $\mathrm{N}_{2}$ fixation), the export flux at the base of the euphotic zone, the deviation from Redfield stoichiometry of both carbon fixation and remineralisation, and the flux attenuation in the upper $1000 \mathrm{~m}$ (i.e. the remineralization length scale). Because the biological responses to increasing temperature, ocean stratification, nutrient availability and ocean acidification are frequently taxa- and ecosystem-specific, Passow and Carlson (2012) concluded that the results of synergistic effects of these variables are challenging to predict, and our ability to predict the sequestration flux was additionally limited by an incomplete understanding of mesopelagic food web functioning and flux attenuation.

Warming and acidification are among the most well constrained effects of climate change on the ocean environment. Three general responses of the MCP to ocean warming and acidification have been proposed. Firstly, changes to seawater chemistry may enhance microbial activity and channel a greater fraction of the photosynthetically fixed carbon into DOC, thus potentially increasing the magnitude of the MCP relative to the other ocean carbon pumps in carbon sequestration (Jiao et al., 2010; Eichinger et al., 2011). Secondly, ocean 
warming would increase ocean stratification (e.g. Capotondi et al., 2012) and hence decrease nutrient supply to the euphotic zone, making the surface layer more oligotrophic; this could increase the channelling of PP towards DOC relative to POC, thus enhancing the role of the MCP in carbon sequestration (Jiao et al., 2010). Thirdly, global changes could shift the microbial dominance and degradative capabilities in the open ocean, which may influence the long-lived DOC reservoir in the ocean as a whole (Jiao et al., 2010).

Here we proceed more systematically than in the studies reported in the previous paragraph, and try to answer the following general question posed by Hansell (2013): “What are the key processes responsible for changing the present-day controls on the RDOC inventory, such that its size can be greatly increased or decreased over a few thousand years, thus impacting the climate?' In order to do so, we examine sequentially the potential effects on the MCP of five climate-driven environmental changes, i.e. increased surface-ocean temperature and water column stratification, changes in the concentration of particulate organic matter and in the rate of thermohaline circulation (and cloud cover), and ocean acidification. We try to address the above question at timescales of 100 to ca. 1000 years, which are relevant to the present episode of anthropogenic climate change. The responses of microbial variables to the above five climate-driven environmental changes and their net effects on carbon sequestration by the MCP will be summarised in Table 4 .

\subsection{Increased surface-ocean temperature}

A mesocosm study with a natural plankton assemblage incubated at in situ and elevated water temperatures ( 2 to $6^{\circ} \mathrm{C}$ higher than in situ) showed three major effects of temperature (Wohlers et al., 2009). Firstly, the respiratory consumption of organic carbon was accelerated relative to autotrophic production, i.e. net community production was reduced. Secondly, the partitioning between POC and DOC was shifted toward enhanced accumulation of DOC; however, it is not known if there was a corresponding increase in the production of SRDOC or RDOC. Thirdly, POC downward export through sinking was significantly reduced. It follows from these results that increasing surface-ocean temperature could enhance the MCP, assuming that the increased accumulation of DOC is accompanied by an increased production of SRDOC and RDOC (these two DOC fractions were not specifically measured during the 30-day mesocosm experiment).

Wohlers et al. (2009) considered their study to be a first step in the acquisition of data needed to provide an integrated representation of upper-ocean, biotically-driven processes. 
Such data are required to gain a quantitative understanding of the processes underlying the responses of marine ecosystems to climate-related environmental changes (here, surfaceocean warming).

\subsection{Increased water-column stratification}

In the present ocean, the highest DOC concentrations (70 to $80 \mu \mathrm{mol} \mathrm{C} \mathrm{kg}^{-1}$ ) are observed in tropical and subtropical surface waters $\left(40^{\circ} \mathrm{N}\right.$ to $\left.40^{\circ} \mathrm{S}\right)$ where, according to Hansell et al. (2009), vertical stratification of the upper water column favours the accumulation of organic matter resistant to biological degradation, whereas the lower concentrations (ca. 40 to $50 \mu \mathrm{mol} \mathrm{C} \mathrm{kg}^{-1}$ ) at the surface at higher latitudes are explained by mixing with low-DOC, deep ocean waters. Most models that couple ocean circulation with biogeochemical fluxes predict that the increased surface-ocean temperature will strengthen density stratification (e.g. Capotondi et al., 2012). This would both lengthen the retention times of POC and DOC in the surface layer, and reduce the replenishment of surface waters in nutrients that had been regenerated below (Doney, 2006). We examine in turn the effects of these two environmental changes on the production of DOC, which is the initial process in the MCP.

The longer retention of organic matter near the ocean surface would increase its exposure to UV radiation. In addition, climate change could cause a decrease in the amount of low-altitude clouds (Lauer et al., 2010), which would increase the total and UV radiation in surface waters. The combined two factors would enhance exposure to UV. Although UV radiation is commonly thought to cause photodegradation of SRDOC or RDOC and thus be a sink for these refractory compounds, it can also convert labile DOC to more recalcitrant forms (Sections 6.1). Hence, the combination of increased water-column stratification and decreased cloud cover could lead to higher conversion of labile forms of DOC into SRDOC and RDOC. The net effect of enhanced UV exposure on SRDOC or RDOC destruction and production could either decrease or increase the magnitude of the MCP. Resolving the predicted effects of climate-related changes in UV exposure on SRDOC and RDOC requires further experimental studies.

The reduction of nutrient replenishment of surface waters would expand oligotrophic conditions in the ocean. This could potentially affect the MCP by two different mechanisms.

Firstly according to Jiao et al. (2010), in oligotrophic systems, a larger proportion of primary production may be channelled to DOC (PER), and part of that DOC could be 
subsequently transformed to SRDOC or RDOC. However, the review of Carlson (2002) on the production and removal processes of DOC concluded that there was little systematic variability of PER across productivity regimes, and that PER did not vary as a function of the nutrient status of the system. Hence changes in water-column stratification are unlikely to influence the MCP through nutrient-mediated changes in PER, i.e. no conclusive effect.

Secondly in oligotrophic systems, phytoplankton are composed predominantly of small cells (i.e. picophytoplankton), and the production of both small and large autotrophs is lower than under nutrient-rich conditions (Barber and Hiscock, 2006). Because decreased phytoplankton mean size would increase the ratio of community respiration to community production (i.e. biomass specific respiration increases with decreasing body mass), there would be slower rate of transformation of low concentrations of reactive carbon (e.g. LDOC and SLDOC) to high concentrations of SRDOC and RDOC by marine microbes and their food web interactions. In addition, increased respiration would decrease the pool of DOC. Hence, decreased phytoplankton mean size could cause decreased production of SRDOC and RDOC, i.e. decreased magnitude of the MCP. This may seem to contradict the increase in the importance of the MCP relative to the BCP in oligotrophic systems proposed by Jiao et al. (2010) and described in Section 5.2, but it is not. The reason is that the proposed increase in the $\mathrm{MCP}: \mathrm{BCP}$ ratio in oligotrophic waters reflected a larger decrease in the $\mathrm{BCP}$ (i.e. low POC export) than would have occurred for the MCP.

\subsection{Change in the concentration of particulate organic matter}

Potential changes in production of $\mathrm{POC}\left(\mathrm{P}_{\mathrm{POC}}\right)$ may be significant for $\mathrm{P}_{\mathrm{DOC}}$ because the solubilisation of organic particles by bacteria is an important source of DOC in the ocean. Although the contribution of the latter process to $\mathrm{P}_{\mathrm{DOC}}$ is not well quantified, changes in $\mathrm{P}_{\mathrm{POC}}$ may thus affect the MCP. The continuing warming of continents and oceans could both lengthen the retention times of POC and DOC in the surface layer, and reduce the replenishment of surface waters in nutrients from deeper waters. We discussed the possible effects of these two environmental changes on $\mathrm{P}_{\mathrm{DOC}}$ in Section 7.2, and we examine here the effects of these same changes on $\mathrm{P}_{\mathrm{POC}}$ based on the review of Passow and Carlson (2012), and the potential influence of changes in $\mathrm{P}_{\mathrm{POC}}$ on $\mathrm{P}_{\mathrm{DOC}}$.

The longer retention of organic matter near the ocean surface could have two opposing effects on phytoplankton production. The higher average mixed layer irradiance resulting from longer retention of phytoplankton in surface waters may either increase previously light limited photosynthesis, or photoinhibit previously light saturated photosynthesis. Hence the 
effect of increased stratification as mediated by solar irradiance could be different according to regions.

The reduction of nutrient replenishment of surface waters would cause both a decrease in global marine photosynthesis, and a shift of phytoplankton assemblages toward small cells. There are, however, other possible nutrient-mediated aspects, which were not reviewed by Passow and Carlson (2012). In some specific locations or at some time periods, climate change may lead to increased wind-driven upwelling and storms, which could enhance the supply of nutrients to surface waters and subsequently increase the competitive advantage of large phytoplankton, such as diatoms, relative to small cells (Falkowski and Oliver, 2007; Finkel et al., 2010). Globally, however, climate change is anticipated to increase ocean stratification and thereby result in reduced nutrient availability in the surface ocean. These changes could favour smaller-sized phytoplankton as they generally have lower nutrient requirements and are thus able to thrive under oligotrophic stratified conditions (Falkowski and Oliver, 2007; Cermeño et al., 2008). For example, predictions from a coupled oceanbiogeochemical model suggest a global decrease in the relative contribution of diatoms to the total algal biomass with a more severe effect at high latitudes, especially in the North Atlantic and the North Pacific Oceans (Bopp et al., 2005).

The above climate-change increases in surface-ocean temperature and water columnstratification could lead to a decrease in $\mathrm{P}_{\mathrm{POC}}$ in the upper water column, and thus a decrease in the concentration of organic particles. This could affect the MCP because one mechanism of $\mathrm{P}_{\mathrm{DOC}}$ is the solubilisation of POC by bacteria, and some of this DOC may be transformed to SRDOC or RDOC (Jiao and Azam, 2011). Hence, a decrease in $\mathrm{P}_{\mathrm{POC}}$ may be accompanied by lower $\mathrm{P}_{\mathrm{DOC}}$ by bacterial POC solubilisation and thus a decrease in the SRDOC or RDOC produced from POC and thus in the MCP. However this will depend on the local importance of $\mathrm{P}_{\mathrm{POC}}$ to $\mathrm{P}_{\mathrm{DOC}>100}$ relative to other sources (e.g. food web) of $\mathrm{P}_{\mathrm{DOC}}>100$.

\subsection{Changes in thermohaline circulation and cloud cover}

A decline in the intensity of thermohaline circulation in the Atlantic Ocean (i.e. Atlantic Meridional Overturning Circulation; IPCC, 2013, 3.6.3) and also perhaps in the Pacific Ocean (McPhaden and Zhan, 2002) during the $21^{\text {st }}$ century is predicted. Although the magnitude of the slowdown is uncertain, there would be a reduction in the rate at which deep waters are returned to the ocean's surface. Once at surface, part of the SRDOC and RDOC contained in the water coming from depth could be photodegraded by the solar UV radiation (Section 6.2), and part of the $\mathrm{CO}_{2}$ dissolved in that water could be degassed to the atmosphere, these two 
losses varying with regions and seasons. It is uncertain if the slowing of the thermohaline circulation would affect differentially the losses of RDOC by photodegradation and of $\mathrm{CO}_{2}$ by degassing, and thus the relative importance of the $\mathrm{MCP}$ and the $\mathrm{BCP}$. There are at least two different scenarios.

If the environmental factors that control the photodegradation of SRDOC and RDOC and the degassing of $\mathrm{CO}_{2}$ remained the same as present, the two carbon losses would decrease by the same proportion as the reduction in thermohaline circulation, and the relative losses of SRDOC and RDOC versus $\mathrm{CO}_{2}$ would not change in the future. Alternatively, the climatechange reduction in the amount of low-level clouds proposed by Lauer et al. (2010; see Section 7.2) would increase the UV radiation in surface waters, which would cause an increased loss rate of the SRDOC and RDOC that were transported from depth to surface. The mechanism would be an alteration of SRDOC and RDOC by protodegradation, followed by microbial remineralisation of the resulting more labile DOC (Section 6.2). At the same time, the increased partial pressure of atmospheric $\mathrm{CO}_{2}$ would decrease the efflux of $\mathrm{CO}_{2}$ from ocean to atmosphere. The increasing loss of SRDOC and RDOC and decreasing loss of $\mathrm{CO}_{2}$ would diminish the amount of carbon sequestered in the ocean under the form of SRDOC and RDOC and increase the amount sequestered under the form of $C_{\mathrm{T}}$. The net result would be a decrease in the importance of the MCP relative to the vertical ocean carbon pumps.

\subsection{Ocean acidification}

A mesocosm experiment conducted with seawater that was aerated with $\mathrm{CO}_{2}$ concentrations identical to the present atmospheric value (controls) and at higher concentrations (and thus lower $\mathrm{pH}$, eq. 2) showed that the plankton community released more $\mathrm{DOC}$ under high $\mathrm{CO}_{2}$ concentrations (Riebesell et al., 2007). If this study can be extrapolated to in situ conditions, an increasingly greater fraction of the carbon fixed by photosynthesis could be channelled into DOC as the ocean will progressively acidify. Part of this DOC could, in the natural environment, be transformed into refractory compounds by the activity of microbes, and thus, according to Eichinger et al. (2011), potentially increase the importance of the MCP.

\subsection{Overall potential effects of climate change on the microbial carbon pump}

Several of the above responses of the MCP to climate-induced changes in environmental characteristics of the ocean are based on the assumption that increased microbial activity will enhance the MCP (Jiao et al. 2010). However, changes in environmental characteristics could increase not only the production of DOC by microbes, but also their remineralisation of DOC 
to $\mathrm{CO}_{2}$, and the net effect of the two processes on carbon budgets is not known (Azam and Jiao, 2011).

Table 4 reports that three of the seven predicted climate-related changes in the ocean environment we reviewed could potentially enhance carbon sequestration by the MCP, and three could diminish it (one could be either way). However because our present knowledge of most MCP processes is at best tentative, we are unable to assess the magnitudes of the potential climate-related increases or decreases in the magnitude of the MCP and their effects on carbon sequestration, or compare these to the magnitudes of predicted changes in the three vertical ocean carbon pumps (for the BCP, see Passow and Carlson, 2012). Despite these uncertainties, Table 4 shows that predicted MCP changes in response to climate-related changes in environmental factors may be counter-intuitive, and their study will require more comprehensive knowledge of details of the MCP processes. Considering the effect of each environmental change separately, as done here, led to some contradictory conclusions concerning carbon sequestration by the MCP (Table 4, last column). A way to resolve these initial contradictions and reduce uncertainties will be through comprehensive modelling studies that will consider the effects of all environmental changes together. The present analysis is a first step toward this integrated approach, which could lead to results that would be different from those obtained here.

\section{Conclusions}

The above predictions about the responses of the MCP to changes in the marine environment caused by climate change were based on combining a limited number of empirical studies, for which data were often scarce, and assumptions, which were not always clearly stated. Assumptions are especially critical when data are not available or are contradictory. The mechanisms and processes examined in Sections 6.1 to 6.3 were based on several such assumptions, which were not always stated explicitly in the literature cited, and their formulation here reflects our understanding of the studies we analysed.

We found that the main gaps in our understanding of the MCP concern the mechanisms of RDOC production and removal. During our review of the relevant literature, we indentified two categories of assumptions concerning the biotic processes of RDOC production, and third category about environmental effects.

The first category considers general food-web effects (Section 6.1). For example, it is generally assumed that some DOC produced in the marine environment is transformed into 
RDOC by the microbial food web, i.e. increased production of DOC leads to increased production of RDOC. Although this assumption may be reasonable, it has not been supported by observational or experimental studies, especially given the difficulty of estimating the rate of RDOC production both at sea or in the laboratory. It is also assumed that successive processing of SLDOC and SRDOC by the microbial food web progressively transforms some of that organic carbon into less and less labile DOC and ultimately RDOC. However, this assumption is largely untested.

The second category of assumptions considers specific mechanisms of RDOC production (Section 6.1). For example, it is assumed that RDOC is exuded directly by phytoplankton, or can be produced directly from cells of heterotrophic microbes by either exudation from active cells (i.e. bacteria transform into RDOC part of the DOC they consume and not use to satisfy their metabolic requirements), or released form cells that are lysed by viruses or grazed by zooplankton. It is also assumed that part of the bulk DOC can be transformed into RDOC by bacterial activity. Finally, it is assumed that the conversion of POC to DOC by ectoenzymes expressed by microorganisms can generate by-products that are resistant to further utilisation by microbes, i.e. RDOC.

A third category of assumptions addresses environmental effects. These include effects of the environment on the MCP, i.e. UV irradiation in surface waters (which occurs on the ocean ventilation timescales), which is assumed to be the main mechanism for degradation of the longer-lived DOC (Sections 6.1 and 6.2), and the nutrient status of the upper ocean (oligotrophic or eutrophic), which is assumed to influence the balance between the BCP and the MCP (Section 5.2). They also include effects of the MCP on the environment, i.e. it is assumed that the longer-lived DOC can be transported downwards by sinking particles (Sections 6.2 and 6.3), and that the MCP does not change the chemistry of seawater (Section 5.1).

Addressing the above assumptions could be part of integrated microbiological and biogeochemical studies of the MCP in coming years. More generally, understanding the full suite of interrelated responses of marine ecosystems to climate-related environmental changes and predicting their impacts on ecosystem dynamics, biogeochemical cycling, and feedbacks to the climate system will require a multidisciplinary effort involving seagoing and experimental marine researchers together with modellers, which would cover the range of models from ecosystems to Atmosphere Ocean General Circulation (Wohlers et al., 2009). As 
suggested in Jiao et al. (2014), this will require original combinations of observational, experimental and modelling studies.

\section{$\underline{\text { Acknowledgements }}$}

We thank Craig A. Carlson, Tim DeVries, Jean-Pierre Gattuso, Richard S. Lampitt, Toshi Nagata, Uta Passow, Fereidoun Rassoulzadegan and Christian Tamburini for useful information related to our study, and Farooq Azam, Nianzhi Jiao, Susanne Neuer, Carol Robinson, Victor Smetacek and Helmuth Thomas for comments following the presentation of a short version of this work to Workshop 2 of the IMBIZO III meeting. We also thank the reviewers of the successive versions of our review for their numerous, very useful comments. This research was supported by funding from Université Pierre et Marie Curie Paris 06 (UPMC) and CNRS to the Villefranche Oceanography Laboratory (LL, MW, LG, and JU), a research professorship from UPMC to RBR, and grants from the Natural Sciences and Engineering Research Council of Canada to RBR. 


\section{References}

Amon, R.M., Benner, R. 1996. Bacterial utilization of different size classes of dissolved organic matter. Limnlogy and Oceanography 41, 41-51.

Archer, D., Buffett, B., Brovkin, V., 2009. Ocean methane hydrates as a slow tipping point in the global carbon cycle. Proceedings of the National Academy of Sciences of the USA 106, 20596-20601.

Azam, F., N. Jiao, N., 2011. Revisiting the ocean's carbon cycle. In: Jiao, N, Azam, F., Sanders, S. (Eds.), Microbial carbon pump in the ocean. Science booklet, Supplement to Science, p. 3, http://science.imirus.com/Mpowered/book/vscim11/i2/p1

Barber, R.T., Hiscock, M.R., 2006. A rising tide lifts all phytoplankton: Growth response of other phytoplankton taxa in diatom-dominated blooms, Global Biogeochemical Cycles 20, GB4S03, doi:10.1029/2006GB002726.

Benner, R., Biddanda, B., 1998. Photochemical transformations of surface and deep marine dissolved organic matter: Effects on bacterial growth. Limnology and Oceanography 43, 1373-1387.

Benner, R., Herndl, G.J., 2011. Bacterially derived dissolved organic matter in the microbial carbon pump. In: Jiao, N, Azam, F., Sanders, S. (Eds.), Microbial carbon pump in the ocean. Science booklet, Supplement to Science, pp. 46-48, http://science.imirus.com/Mpowered/book/vscim11/i2/p1

Bopp L., Aumont, O., Cadule, P., Alvain, S, Gehlen, M., 2005. Response of diatoms distribution to global warming and potential implications: A global model study, Geophysical Research Letters 32(L19606), doi:10.1029/2005GL023653.

Brophy, J.E., Carlson, D.J., 1989. Production of biologically refractory dissolved organic carbon by natural seawater microbial populations. Deep-Sea Research A 36, 497-507.

Capotondi, A., Alexander, M.A., Bond, N.A., Curchitser, E.N., Scott, J., 2012. Enhanced upper-ocean stratification with climate change in the CMIP3 models, Journal of Geophysical Research, 117 (C4) doi:10.1029/2011JC007409.

Carlson, C.A., 2002. Production and removal processes. In: Hansell, D.A., Carlson, C.A. (Eds.), Biogeochemistry of marine dissolved organic matter, Academic Press, San Diego, pp. $91-152$. 
Carlson, C.A., Hansell, D.A., Nelson, N.B., Siegel, D.A., Smethie, W.M., et al., 2010. Dissolved organic carbon export and subsequent remineralization in the mesopelagic and bathypelagic realms of the North Atlantic basin. Deep-Sea Research II 57, 1433-1445.

Carlson, C.A, Hansell, D.A., Tamburini, C., 2011. DOC persistence and its fate after export within the ocean interior. In: Jiao, N, Azam, F., Sanders, S. (Eds.), Microbial carbon pump in the ocean. Science booklet, Supplement to Science, pp. 57-59 http://science.imirus.com/Mpowered/book/vscim11/i2/p1

Carr, M.-E., Friedrichs, M.A.M., Schmeltz, M., Aita, M.N., Antoine, D., Arrigo, K.R., Asanuma, I., Aumont, O., Barber, R., Behrenfeld, M., Bidigare, R., Buitenhuis, E.T., Campbell, J., Ciotti, A., Dierssen, H., Dowell, M., Dunne, J., Esaias, W., Gentili, B., Gregg, W., Groom, S., Hoepffner, N., Ishizaka, J., Kameda, T., Le Quéré, C., Lohrenz, S., Marra, J., Mélin, F., Moore, J., Morel, A., Reddy, T.E., Ryan, J., Scardi, M., Smyth, T., Turpie, K., Tilstone, G., Waters, K., Yamanaka, Y., 2006. A comparison of global estimates of marine primary production from ocean color. Deep-Sea Research II, 53, 741-770.

Cermeño P., Dutkiewicz, S., Harris, R.P., Follows, M., Schofield, O., Falkowski, P.G., 2008. The role of nutricline depth in regulating the ocean carbon cycle, Proceedings of the National Academy of Sciences of the USA 105, 20344-20349.

DeVries, T.J., F.W. Primeau, Deursch, C.A., 2014. Quantifying and comparing the microbial and biological carbon pumps in the ocean. Abstract, Ocean Sciences Meeting, Honolulu, Hawaii, USA. http://www.sgmeet.com/osm2014/viewabstract.asp?AbstractID=17345

Dickson, A.G., 1981. An exact definition of total alkalinity and a procedure for the estimation of alkalinity and total inorganic carbon from titration data. Deep-Sea Research 28A, 609-623. Doney, S.C., 2006. Plankton in a warmer world. Nature 444, 695-696.

Dittmar, T., Paeng., J., 2009. A heat-induced molecular signature in marine dissolved organic matter. Nature Geoscience 2, 175-179.

Doney, S.C., Balch, W.M., Fabry, V.J., Feely, R.A.. 2009. Ocean Acidification: A Critical Emerging Problem for the Ocean Sciences. Oceanography 22(4):16-25, http://dx.doi.org/10.5670/oceanog.2009.93.

Druffel, E.R.M., Williams, P.M., Bauer, J.E., Ertel, J.R., 1992. Cycling of dissolved and particulate organic matter in the open ocean. Journal of Geophysical Research 97, 1563915659. 
Eichinger, M. Kooijman, S.A.L.M., Sempéré, R., Lefèvre, D., Grégori, G., Charrière, B., Poggiale, J.C., 2009. Consumption and release of dissolved organic carbon by marine bacteria in a pulsed-substrate environment: from experiments to modelling. Aquatic Microbial Ecology, 56: 41-54.

Eichinger, M., Poggiale, J.C., Sempéré, R., 2011. Toward a mechanistic approach to modeling bacterial DOC pathways: A review. In: Jiao, N, Azam, F., Sanders, S. (Eds.), Microbial carbon pump in the ocean. Science booklet, Supplement to Science, pp. 66-68, http://science.imirus.com/Mpowered/book/vscim11/i2/p1

Falkowski, P.G., Oliver, M., 2007. Mix and match: How climate selects phytoplankton, Nature, 5, 813-819.

Fasham, M.J.R., Boyd, P.W., Savidge, G., 1999. Modeling the relative contributions of autotrophs and heterotrophs to carbon flow at a Lagrangian JGOFS station in the Northeast Atlantic: The importance of DOC, Limnology and Oceanography, 44, 80-94.

Finkel, Z.V., Beardall, J., Flynn, K.J., Quigg, A., Rees, T.A.V., Raven, J.A., 2010.

Phytoplankton in a changing world: cell size and elemental stoichiometry, Journal of Plankton Research, 32, 119-137.

Frankignoulle, M., Canon, C., Gattuso, J.P., 1994, Marine calcification as a source of carbon dioxide: Positive feedback of increasing atmospheric $\mathrm{CO}_{2}$. Limnology and Oceanography 39, $458-462$.

Gattuso, J.P., Frankignoulle, M., Smith, S.V., 1999. Measurement of community metabolism and significance in the coral reef $\mathrm{CO}_{2}$ source-sink debate Proceedings of the National Academy of Sciences of the USA 96, 13017-13022.

Gruber, D.F., Simjouw, J.P., Seitzinger, S.P., Taghon, G.L., 2006. Dynamics and characterization of refractory dissolved organic matter produced by a pure bacterial culture in an experimental predator-prey system. Applied and Environmental Microbiology, 72, 41844191, doi: 10.1128/AEM.02882-05

Guidi, L., J. Uitz, J., L. Legendre, L., ms. An optical-based approach to estimate natural carbon sequestration in the deep ocean from surface export.

Hansell, D.A., 2013. Recalcitrant Dissolved Organic Carbon Fractions. Annual Review of Marine Science 5, 3.1-3.25, doi: 10.1146/annurev-marine-120710-100757

Hansell, D.A., Carlson, C.A., Repeta, D.J., Schlitzer, R., 2009. Dissolved organic matter in 
the ocean: new insights stimulated by a controversy. Oceanography $22,52-61$.

Hansell, D.A., Carlson, C.A., Schlitzer, R., 2012. Net removal of major marine dissolved organic carbon fractions in the subsurface ocean. Global Biogeochemical Cycles, 26, GB1016, doi:10.1029/2011GB004069.

Heinze, C., Maier-Reimer, E., Winn, K., 1991, Glacial $\mathrm{pCO}_{2}$ reduction by the world ocean: Experiment with the Hamburg Carbon Cycle Model. Paleoceanography 6, 395-430.

Henson, S.A., Sanders, R., Madsen, E., 2012. Global patterns in efficiency of particulate organic carbon export and transfer to the deep ocean. Global Biogeochemical Cycles, 26, GB1028, doi:10.1029/2011GB004099.

Hertkorn, N., Benner, R., Frommberger, M., Schmitt-Kopplin, P., Witt, M., Witt, M., Kaiser, K., Kettrup, A., Hedges, J. I., 2006. Characterization of a major refractory component of marine dissolved organic matter. Geochim. Cosmochim. Acta 70, 2990-3010.

Herzog, H., K. Caldeira, and J. Reilly, 2003: An issue of permanence: Assessing the effectiveness of temporary carbon storage. Climatic Change, 59, 293-310.

Honjo, S., Eglinton, T.I., Taylor, C.D., Ulmer, K.M., Sievert, S.M., Bracher, A., German, C.R., Edgcomb, V., Francois, R., Iglesias-Rodriguez, M.D., van Mooy, B., Repeta, D.J., 2014. Understanding the role of the biological pump in the global carbon cycle: An imperative for ocean science. Oceanography 27(3), 10-16, http://dx.doi.org/10.5670/oceanog.2014.78.

Honjo, S., Manganini, S.J., Krishfield, R.A., Francois, R., 2008. Particulate organic carbon fluxes to the ocean interior and factors controlling the biological pump: A synthesis of global sediment trap programs since 1983. Progress in Oceanography 76, 217-285.

IPCC, 2007. Climate change 2007: Synthesis report. Contribution of working groups I, II and III to the fourth assessment report of the Intergovernmental Panel on Climate Change. IPCC, Geneva

IPCC, 2013. Climate change 2013: The physical science basis. Contribution of Working Group I to the Fifth Assessment Report of the Intergovernmental Panel on Climate Change. Stocker, T.F., D. Qin, G.-K. Plattner, M. Tignor, S.K. Allen, J. Boschung, A. Nauels, Y. Xia, V. Bex, Midgley, P.M. (Eds.), Cambridge University Press, Cambridge, United Kingdom and New York, NY, USA, 1535 pp.

Jiao, N., F. Azam, F., 2011. Microbial carbon pump and its significance for carbon sequestration in the ocean. In: Jiao, N, Azam, F., Sanders, S. (Eds.), Microbial carbon pump 
in the ocean. Science booklet, Supplement to Science, pp. 43-45, http://science.imirus.com/Mpowered/book/vscim11/i2/p1

Jiao, N., Herndl, G.J., Hansell, D.A., Benner, R., Kattner, G., Wilhelm, S.W., Kirchman, D.L., Weinbauer, M.G., Luo, T., Chen F., Azam, F., 2010. Microbial production of recalcitrant dissolved organic matter: long-term carbon storage in the global ocean, Nature Reviews Microbiology 8, 593-599.

Jiao, N., Herndl, G.J., Hansell, D.A., Benner, R., Kattner, G., Wilhelm, S.W., Kirchman, D.L., Weinbauer, M.G., Luo, T., Chen F., Azam, F., 2011. The microbial carbon pump and the oceanic recalcitrant dissolved organic matter pool. Nat. Rev. Microbiol 9, 555-555, doi:10.1038/nrmicro2386-c5

Jiao, N., Robinson, C., Azam, F., Thomas, H., Baltar, F., Dang, H., Hardman-Mountford, N. J., Johnson, M., Kirchman, D. L., Koch, B. P., Legendre, L., Li, C., Liu, J., Luo, T., Luo, Y.W., Mitra, A., Romanou, A., Tang, K., Wang, X., Zhang, C., Zhang, R., 2014. Mechanisms of microbial carbon sequestration in the ocean - future research directions. Biogeosciences Discussion, 11, 7931-7990, doi:10.5194/bgd-11-7931-2014

Kaiser and Benner, 2009 Kaiser, K., Benner, R., 2009. Biochemical composition and size distribution of organic matter at the Pacific and Atlantic time-series stations. Marine Chemistry $113,63-77$.

Kattner, G., Simon, M., Koch, B.P., 2011. Molecular characterization of dissolved organic matter and constraints for prokaryotic utilization. In: Jiao, N, Azam, F., Sanders, S. (Eds.), Microbial carbon pump in the ocean. Science booklet, Supplement to Science, pp. 60-61, http://science.imirus.com/Mpowered/book/vscim11/i2/p1

Keil, R.G., Kirchman, D.L., 1994. Abiotic transformation of labile protein to refractory protein in sea water. Marine Chemistry 45, 187-196.

Kieber, R.J., Hydro, L.H., Seaton, P.J., 1997. Photooxidation of triglycerides and fatty acids in seawater: Implication toward the formation of marine humic substancesLimnology and Oceanography 42, 1454-1462.

Kujawinski. E.B., 2011. The impact of microbial metabolism on marine dissolved organic matter. Annual Review of Marine Science 3, 567-599.

Kwon, E.Y., Primeau, F., Sarmiento, J. L., 2009. The impact of remineralization depth on the air-sea carbon balance. Nature Geoscience, 2, 630-635, doi:10.1038/ngeo612. 
Lampitt, R.S., Achterberg, E.P., Anderson, T.R., Hughes, J.A., Iglesias-Rodriguez, M.D., Kelly-Gerreyn, B.A., Lucas, M., Popova, E.E., Sanders, R., Shepherd, J.G., Smythe-Wright, D., Yool, A., 2008 Ocean fertilization: a potential means of geoengineering? Philosophical Transactions of the Royal Society of London A 366: 3919-3945, doi:

10.1098/rsta.2008.0139.

Lauer, A., Hamilton, K., Wang, Y., Phillips, V. T. J., Bennartz, R., 2010. The impact of global warming on marine boundary layer clouds over the eastern pacific. A regional model study. Journal of Climate, 23, 5844-5863, doi: 10.1175/2010JCLI3666.1.

Legendre, L., Le Fèvre, J., 1991. From individual plankton cells to pelagic marine ecosystems and to global biogeochemical cycles. In: Demers, S. (Ed.), Particle analysis in oceanography Springer-Verlag, Berlin., pp. 261-300.

Legendre, L., Le Fèvre, J., 1995. Microbial food webs and the export of biogenic carbon in oceans. Aquatic Microbial Ecology 9, 69-77.

Legendre, L., Rassoulzadegan, F., 1996. Food-web mediated export of biogenic carbon in oceans: environmental control. Marine Ecology Progress Series 145, 179-193.

Legendre, L., Rivkin, R., 2008. Planktonic food webs: microbial hub approach. Marine Ecology Progress Series 365, 289-309.

Le Quéré, C., Harrison, S. P., Prentice, I.C., Buitenhuis, E. T., Aumont, O., Bopp, L., Claustre, H., Cotrim da Cunha, L., Geider, R., Giraud, X., Klaas, C., Kohfeld, K. E., Legendre, L., Manizza, M., Platt, T., Rivkin, R. B., Sathyendranath, S., Uitz, J., Watson, A. J., Wolf-Gladrow, D., 2005. Ecosystem dynamics based on plankton functional types for global ocean biogeochemistry models. Global Change Biology, 11, doi:10.11111/j.13652486.2005.01004.x, pp 2016-2040.

Lutz, M. J., Caldeira, K., Dunbar, R. B., Behrenfeld, M. J., 2007. Seasonal rhythms of net primary production and particulate organic carbon flux to depth describe the efficiency of biological pump in the global ocean, Journal of Geophysical Research-Oceans, 112(C10), Artn C10011, doi:0.1029/2006jc003706.

Marañón, E., Cermeño, P., Fernàndez, E., Rodrìguez, J., Zabala, L., 2004. Significance and mechanisms of photosynthetic production of dissolved organic carbon in a coastal eutrophic ecosystem. Limnology and Oceanography 49, 1652-1666.

Martin, J.H., Knauer, G.A., Karl, D.M., Broenkow, W.W., 1987. Vertex: Carbon cycling in 
the northeast Pacific. Deep-Sea Research, 34: 267-285.

McCarthy, M.D, Beaupré, S.R., Walker, B.D., Voparil, I., Guilderson, T.P., Druffel, E.R.M., 2011. Chemosynthetic origin of 14C-depleted dissolved organic matter in a ridge-flank hydrothermal system. Nature Geoscience 4, 32-36

McPhaden, M.J., Zhang, D., 2002. Slowdown of the meridional overturning circulation in the upper Pacific Ocean. Nature 415, 603-608.

Mopper, K., Zhou, X., Kieber, R.J., Kieber, D.J., Sikorski, R.J., Jones, R.D., 1991.

Photochemical degradation of dissolved organic carbon and its impact on the oceanic carbon cycle. Nature 353, 60-62.

Moran, M.A., Zepp, R.G., 1997. Role of photoreactions in the formation of biologically labile compounds from dissolved organic matter. Limnology and Oceanography 42, 1307-1316.

Naganuma, T. et al., 1996. Konishi, S., Inoue, T., Nakane, T., Sukizaki, S., 1996.

Photodegradation or photoalteration? Microbial assay of the effect of UV-B on dissolved organic matter. Marine Ecology Progress Series 135, 309-310.

Nagata, T. 2000. Production mechanisms of dissolved organic matter. In: Kirchman, D.L. (Ed.), Microbial ecology of the oceans, 1st ed. Wiley-Liss, NewYork, pp. 121-152.

Nagata, T., 2008. Organic matter-bacteria interactions in seawater. In: Kirchman, D.L. (Ed.), Microbial ecology of the oceans, 2nd ed. John Wiley \& Sons, Inc., Hoboken, pp. 207-241.

Ogawa, H., Tanoue, E., 2003. Dissolved organic matter in oceanic waters. Journal of Oceanography 59: 129-147.

Orellana, M.V, Pang, W.L., Durand, P.M., Whitehead, K., Baliga, N.S., 2013. A role for programmed cell death in the microbial loop. PLoS ONE 8, e62595, 1-12.

doi:10.1371/journal.pone.0062595

Osterholz, H., Dittmar, T., Niggemann, J., 2014 Molecular evidence for rapid dissolved organic matter turnover in Arctic fjords. Marine Chemistry 160,1-10.

Passow, U., Carlson, C.A., 2012. The biological pump in a high $\mathrm{CO}_{2}$ world. Marine Ecology - Progress Series 470, 249-271, doi: 10.3354/meps09985.

Riebesell, U., Schulz, K.G., Bellerby, R.G.J., Botros, M., Fritsche, P., Meyerhöfer, M., Neill, C., Nondal, G., Oschlies, A., Wohlers, J., Zöllner, E., 2007. Enhanced biological carbon consumption in a high $\mathrm{CO}_{2}$ ocean. Nature 450, 545-548. 
Romano, S., Dittmar, T., Bondarev, V., Weber, R.J.M., Viant, M.R., Schulz-Vogt, H.N., 2014. Exo-Metabolome of Pseudovibrio sp. FO-BEG1 analyzed by ultra-high resolution mass spectrometry and the effect of phosphate limitation PLoS ONE 9(5): e96038.

doi:10.1371/journal.pone.0096038

Sarmiento, J.L., Gruber, N., 2006. Ocean biogeochemical dynamics. Princeton Univ. Press, $528 \mathrm{pp}$.

Sarmiento, J.J., Toggweiler, J.R., 1984. A new model for the role of the oceans in determining atmospheric $\mathrm{P}_{\mathrm{CO} 2}$. Nature, 308, 621-624.

Sigman, D.M., Haug, G.H., 2003. The biological pump in the past. In: Elderfield, H. (Ed.), Holland, H.D., Turekian, K.K. (Exec. Eds.) Treatise on geochemistry. Vol. 6. Elsevier, pp. 491-528.

Stedmon, C.A., Alvarez-Salgado, X.A., 2011. Spectroscopic characterization of marine dissolved organic matter. In: Jiao, N, Azam, F., Sanders, S. (Eds.), Microbial carbon pump in the ocean. Science booklet, Supplement to Science, pp. 62-63, http://science.imirus.com/Mpowered/book/vscim11/i2/p1

Stoderegger, K., Herndl, G.J., 1998. Production and release of bacterial capsular material and its subsequent utilization by marine bacterioplankton. Limnology and Oceanography 43,877884.

Stoderegger, K., Herndl, G.J., 1999. Production of exopolymer particles by marine bacterioplankton under contrasting turbulence conditions. Marine Ecology Progress Series 189, 9-16.

Stubbins, A., Niggemann, J., Dittmar. T., 2012. Photo-lability of deep ocean dissolved black carbon. Biogeosciences 9, 1661-1670.

Tranvik, L.J., Bertilsson, S., 2001. Contrasting effects of solar UV radiation on dissolved organic sources for bacterial growth. Ecology Letters 4, 458-463.

Turner, J.T., 2014, Zooplankton fecal pellets, marine snow, phytodetritus and the ocean's biological pump, Progress in Oceanography (2014), doi:

http://dx.doi.org/10.1016/j.pocean.2014.08.005

UNFCC (United Nations Framework Convention on Climate Change), 1998. Methodological issues related to the Kyoto Protocol. Report of the Conference of the Parties on its third session, held at Kyoto from 1 to 11 December 1997. Addendum Part Two: Action taken by 
the Conference of the Parties at its third session. FCCC/CP/1997/7/Add.1, 28 March 1998.

Verhoeven, J.W., 1996. Glossary of terms used in photochemistry. Pure \& Applied Chemistry $68,2223-2286$.

Volk, T., Hoffert, M.I., 1985. Ocean carbon pumps: analysis of relative strength and efficiencies of in ocean-driven circulation atmospheric $\mathrm{CO}_{2}$ changes. In: Sundquist, E.T., Broecker, W.S. (Eds.), The carbon cycle and atmospheric CO2: Natural variation Archean to Present. AGU Monograph 32, American Geophysical Union, Washington, DC, pp. 99-110. Ware, J. R., Smith, S. V., Reaka-Kudla, M. L., 1992. Coral reefs: Sources or sinks of atmospheric $\mathrm{CO}_{2}$ ? Coral Reefs 11, 127-130.

Weinbauer, M.G., Chen, F., Wihelm, S.W., 2011. Virus-mediated redistribution and partitioning of carbon in the global oceans. In: Jiao, N, Azam, F., Sanders, S. (Eds.)., Microbial carbon pump in the ocean. Science booklet, Supplement to Science, pp 54-56, http://science.imirus.com/Mpowered/book/vscim11/i2/p1

Wohlers, J., Engel, A., Zöllner, E., Breithaupt, P., Jürgens, K., Hoppe, H.J., Sommer, U., Riebesell, U., 2009. Changes in biogenic carbon flow in response to sea surface warming. Proceedings of the National Academy of Sciences of the USA 106, 7067-7072.

Zeebe, R.E. 2012. History of seawater carbonate chemistry, atmospheric $\mathrm{CO}_{2}$, and ocean acidification. Annual Review of Earth and Planetary Sciences 40,141-65 doi: 10.1146/annurev-earth-042711-105521

Zeebe, R.E., Wolf-Gladrow, D.A. 2008. Carbon dioxide, dissolved (ocean). In: Gornitz, V. (Ed.), Encyclopedia of paleoclimatology and ancient environments. Encyclopedia of Earth Sciences Series, Springer, Berlin, Heidelberg, New York. 
Figure 1. Vertical profiles of DOC, $C_{\mathrm{T}}$, and $A_{\mathrm{T}}$ in the North Atlantic Ocean. (A) The DOC profile was extracted from Fig. 5 of Hansell (2013). (B) The $C_{\mathrm{T}}$ and $A_{\mathrm{T}}$ profiles were digitized from Fig. 3 of Zeebe and Wolf-Gladrow (2008). Panel A: Hansell (2013) considers that values $<67 \mu \mathrm{mol} \mathrm{kg}{ }^{-1}$ (i.e. surface maximum), from surface to ca. $100 \mathrm{~m}$, correspond to RDOC+SRDOC+SLDOC; $<56 \mu \mathrm{mol} \mathrm{kg}{ }^{-1}$, from ca. 100 to $1000 \mathrm{~m}$, to RDOC+SRDOC; and $<44 \mu \mathrm{mol} \mathrm{kg}{ }^{-1}$, at $>1000 \mathrm{~m}$, to RDOC only.

Figure 2. Four ocean carbon pumps defined in Sections 2 and 4. The small numbers in full or open circles identify arrows in the Figure. The observed vertical gradient of $\mathrm{C}_{\mathrm{T}}$ in the World Ocean (Fig. 1) is maintained by the action of three vertical carbon pumps: the carbonate pump, i.e. bio-precipitation of $\mathrm{CaCO}_{3}$ in the upper water column (which is accompanied by the release of $\mathrm{CO}_{2}$ ), followed by sinking of bio-mineral particles to depth where their carbon is sequestered the solubility pump, i.e. dissolution of atmospheric $\mathrm{CO}_{2}$ in surface waters followed by deep mixing of the $\mathrm{CO}_{2}$-rich water and sequestration ; and the $\mathrm{BCP}$, i.e. photosynthetic uptake of carbon by phytoplankton and its transformation by the food web in the euphotic zone, including respiration

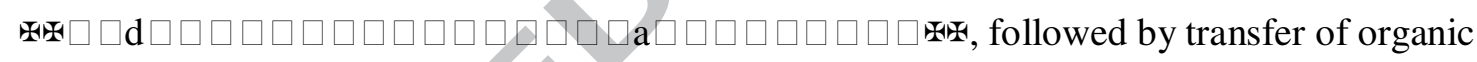
carbon into deep waters where it is sequestered ${ }^{*}$. By maintaining the vertical gradient in $\mathrm{C}_{\mathrm{T}}$, the carbon pumps regulate the exchange of $\mathrm{CO}_{2}$ between the atmosphere and the ocean. Inorganic and organic carbon that is transferred below the euphotic zone or the seasonal surface mixed layer (represented here by the $100 \mathrm{~m}$ depth horizon) is considered to be exported, and the fraction of exported carbon that does not return to surface waters and the atmosphere within 100 years is considered to be sequestered, which is the case for carbon that reaches the average depth of ca. $1000 \mathrm{~m}$ in the ocean. During the downward transit from 100 to $1000 \mathrm{~m}, \mathrm{CO}_{2}$ is released in the water column by dissolution of part of the sinking $\mathrm{CaCO}_{3}$ wand remineralisation of part of the organic carbon that is transferred to depth $\mathrm{CO}_{2}$ that "leaks" (i.e. escapes) from the three carbon pumps above the depth of sequestration may return to the surface by upward mixing, where it can be exchanged with the atmosphere (* to ). Below the average ca. $1000 \mathrm{~m}$ depth, carbon is either entrained in the deep-ocean circulation, which has a characteristic turnover time of ca. 1000 years, or buried in sediments where it enters cycles that last millions of years. The production of RDOC and SRDOC with a 
lifetime $\geq 100$ years (i.e. DOC $>100$, from POC and less refractory DOC, i.e. SLDOC and SRDOC), presumably by microbial activity, will sequester ocean carbon because their

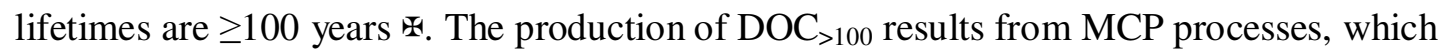
maintain the large gradient that exists between short-lived and long-lived DOC. Production of $\mathrm{DOC}_{>100}$ is thought to take place mainly in surface waters, but it may occur at all depths; the resulting RDOC is distributed over all oceans depths. Additional details concerning the functioning of the BCP are given in Fig. 1 of Passow and Carlson (2012). The numbers in black or open circles are used to identify arrows in the text.

Figure 3. Combined effects of the four ocean carbon pumps on $C_{\mathrm{T}}$ and $A$, represented on a figure that originally illustrated the carbonate chemistry of a water parcel in the surface ocean. The changes in $C_{\mathrm{T}}$ and $A_{\mathrm{T}}$ that may accompany the four pumps are described in Sections 2 and 4.2. The effect of total (heterotrophic) respiration on decreasing $A_{\mathrm{T}}$ is approximately partitioned between the MCP (shaded triangle) and the BCP (area between the shaded triangle and the dotted line), considering that heterotrophic respiration associated with the carbonate pump is very small. Surface waters are the site of net photosynthesis (i.e. photosynthesis > autotrophic respiration), exchanges of $\mathrm{CO}_{2}$ with the atmosphere, and calcification. Deep waters are characterised by the invasion of sea-surface $\mathrm{CO}_{2}$, remineralisation of organic carbon (heterotrophic respiration), and dissolution of $\mathrm{CaCO}_{3}$. The positions of the lines correspond to $\mathrm{T}=15^{\circ} \mathrm{C}, \mathrm{S}=35$, and $\mathrm{P}=1 \mathrm{~atm}$. Adapted from Zeebe and Wolf-Gladrow (2008, their Fig. 2).

Figure 4. World-ocean integrated, euphotic zone production rates of LDOC, SLDOC, SRDOC and RDOC plotted as a function of their average lifetimes (values from Hansell, 2013, his Table 1). The production rates of SLDOC, SRDOC are from modelling of Hansell et al. (2012), who used these values to obtain satisfactory agreement between DOC concentrations in their global biogeochemical model and observations. The equation of the linear regression line on the four points is given in the text (eq. 8). The vertical dotted line corresponds to a DOC lifetime of 100 years. The two horizontal double-arrowed dotted lines represent the values of $\mathrm{P}_{\mathrm{DOC}<100}$ and $\mathrm{P}_{\mathrm{DOC}>100}$, respectively. 
Figure 5. Schematic representation of autotrophic production and food-web transformation of DOC and POC in the ocean. (1) Assuming that PER $=20 \%$, total PP $=50 \mathrm{Gt} \mathrm{C}_{\text {year }}{ }^{-1}$ is partitioned between $\mathrm{PP}_{\mathrm{DOC}}$ and $\mathrm{PP}_{\mathrm{POC}}=10$ and $40 \mathrm{Gt} C$ year $^{-1}$. (2) Assuming that $50 \%$ of $\mathrm{PP}_{\mathrm{POC}}$ are transformed into DOC by the heterotrophic food web, then $\mathrm{P}_{\mathrm{DOC}}=30 \mathrm{Gt} \mathrm{C}$ year ${ }^{-1}$, and the remaining $20 \mathrm{Gt} \mathrm{C}_{\mathrm{Cear}}{ }^{-1}$ are food-web transformed into heterotrophic or detrital POC ( $\mathrm{P}_{\mathrm{POC}}$ ) or respired back to $\mathrm{CO}_{2}(\mathrm{R})$. (3) Further food-web activity respires most $\mathrm{P}_{\mathrm{DOC}}$ and $\mathrm{P}_{\mathrm{POC}}$ back to $\mathrm{CO}_{2}$, the remainder being the MCP and BCP sequestration. The sizes of the $\mathrm{P}_{\mathrm{DOC}}$ and $\mathrm{P}_{\mathrm{POC}}$ compartments in the bottom horizontal box are proportionally much bigger than the $\sim 1 \%$ of PP that is actually sequestered annually. 


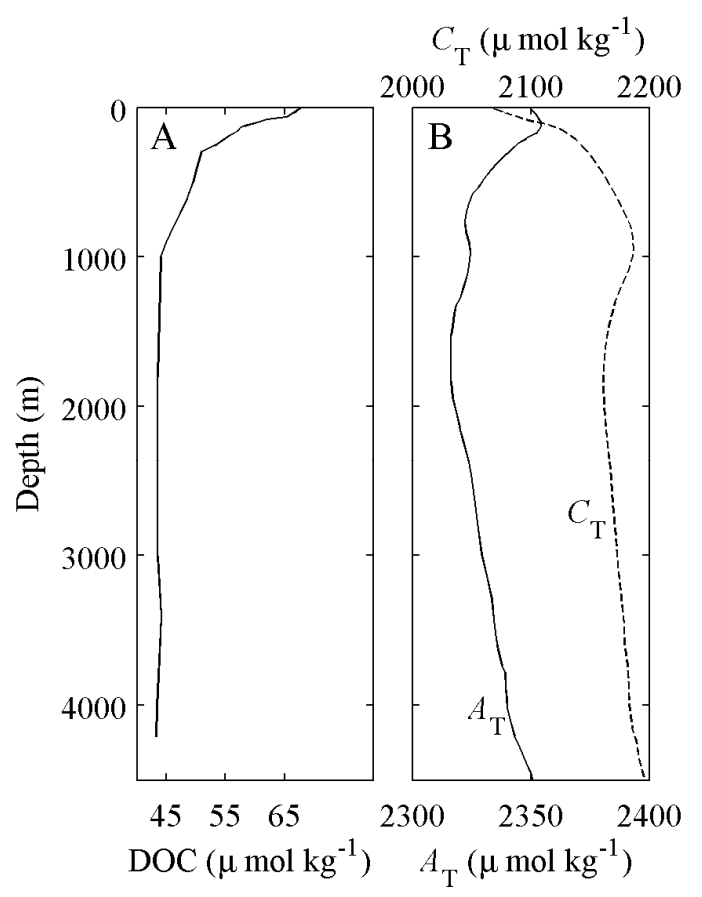


THE OCEAN CARBON PUMPS

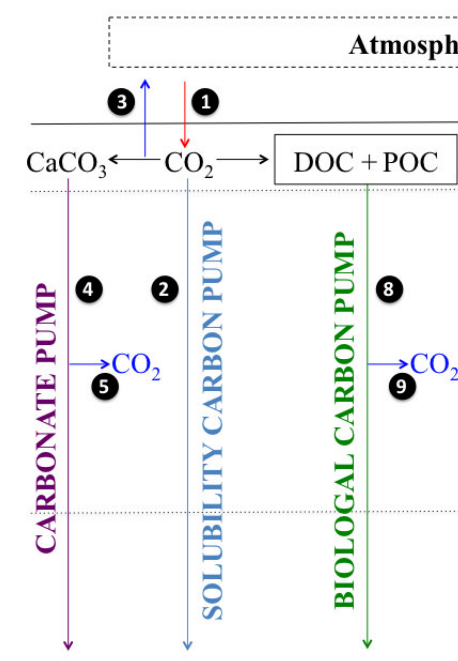

CARBON

PROCESSES

Dissolution of atmospheric $\mathrm{CO}_{2}$ Biotransformation $\stackrel{\text { (10) }}{\longrightarrow} \mathrm{CO}_{2}$

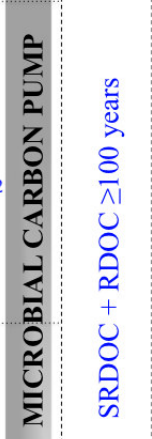
$\mathrm{CO}_{2}$ 10 years

to surface (1) (2) $1 \mathrm{CaCO}_{3}$ dissolution remineralisation 100 years Upward $\mathrm{CO}_{2}$ mixing to surface $1000 \mathrm{~m}=$ Sequestration $\geq 1000$ years to surface

The chemical forms of $\mathrm{CO}_{2}$ in seawater are: $\mathrm{CO}_{2}$ (diss), $\mathrm{HCO}_{3}{ }^{-}$, and $\mathrm{CO}_{3}{ }^{2-}$ 


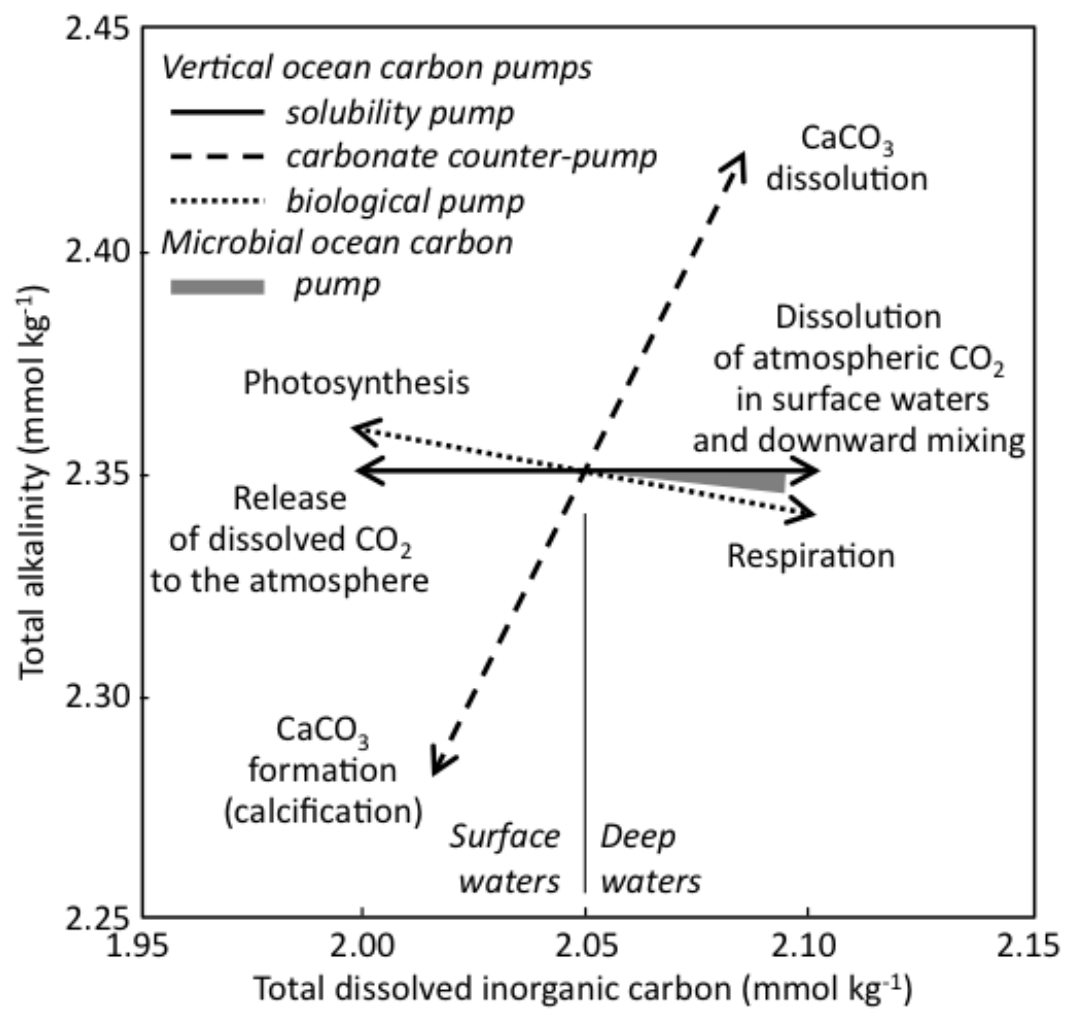




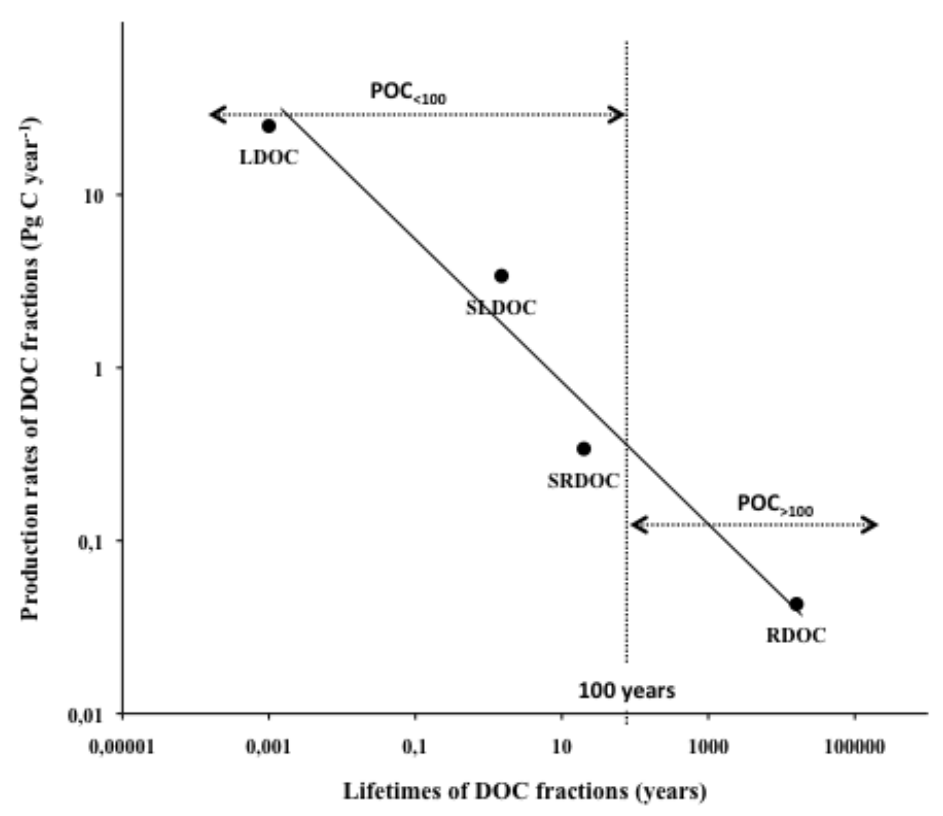




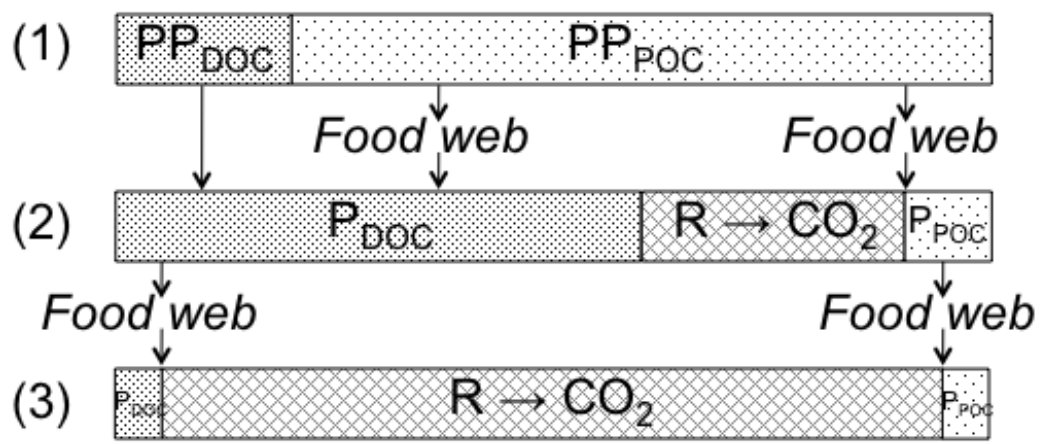


Table 1. Acronyms and symbols of quantities in the present text, definitions, areal dimensions, and corresponding units often used in oceanography. N/A: not applicable.

\begin{tabular}{|c|c|c|c|}
\hline $\begin{array}{l}\text { Acronym } \\
\text { or symbol }\end{array}$ & Definition & Dimensions & Units* \\
\hline$A_{\mathrm{T}}$ & Total alkalinity & $\mathrm{NM}^{-1}$ & $\mu \mathrm{mol} \mathrm{kg}{ }^{-1}$ \\
\hline$b$ & Remineralisation exponent & $\begin{array}{l}\text { Dimension- } \\
\text { less }\end{array}$ & \\
\hline $\mathrm{BCP}$ & Biological carbon pump & $\mathrm{ML}^{-2} \mathrm{~T}^{-1}$ & $\mathrm{~g} \mathrm{C} \mathrm{m}^{-2}$ year $^{-1}$ \\
\hline CDR & Carbon dioxide removal (methods) & N/A & N/A \\
\hline$C_{\mathrm{T}}$ & Total dissolved inorganic carbon & $\mathrm{ML}^{-2}$ & $\mathrm{~g} \mathrm{C} \mathrm{m}^{-2}$ \\
\hline DIC & Dissolved inorganic carbon; see $C_{\mathrm{T}}$ & $\mathrm{ML}^{-2}$ & \\
\hline DOC & Dissolved organic carbon & $\mathrm{ML}^{-2}$ & $\mathrm{~g} \mathrm{C} \mathrm{m}^{-2}$ \\
\hline $\mathrm{DOC}_{<100}$ & DOC with an average lifetime $<100$ years & $\mathrm{ML}^{-2}$ & $\mathrm{~g} \mathrm{C} \mathrm{m}^{-2}$ \\
\hline $\mathrm{DOC}_{>100}$ & DOC with an average lifetime $>100$ years & $\mathrm{ML}^{-2}$ & $\mathrm{~g} \mathrm{C} \mathrm{m}^{-2}$ \\
\hline DOM & Dissolved organic matter & $\mathrm{ML}^{-2}$ & $\mathrm{~g} \mathrm{~m}^{-2}$ \\
\hline$F_{e}$ & $\begin{array}{l}\text { Downward POC flux at depth } z_{e} \text {; export } \\
\text { flux }\end{array}$ & $\mathrm{ML}^{-2} \mathrm{~T}^{-1}$ & $\mathrm{~g} \mathrm{C} \mathrm{m}^{-2}$ year $^{-1}$ \\
\hline$F_{s}$ & $\begin{array}{l}\text { Downward POC flux at depth } z_{s} \\
\text { sequestration flux }\end{array}$ & $\mathrm{ML}^{-2} \mathrm{~T}^{-1}$ & $\mathrm{~g} \mathrm{C} \mathrm{m}^{-2}$ year $^{-1}$ \\
\hline GWP & Global Warming Potential (indices) & $\begin{array}{l}\text { Dimension- } \\
\text { less }\end{array}$ & N/A \\
\hline LDOC & Labile DOC & $\mathrm{ML}^{-2}$ & $\mathrm{~g} \mathrm{C} \mathrm{m}^{-2}$ \\
\hline MCP & Microbial carbon pump & $\mathrm{ML}^{-2} \mathrm{~T}^{-1}$ & $\mathrm{~g} \mathrm{C} \mathrm{m}^{-2}$ year $^{-1}$ \\
\hline$p \mathrm{CO}_{2}$ & Partial pressure of $\mathrm{CO}_{2}$ & $\mathrm{ML}^{-1} \mathrm{~T}^{-2}$ & atm, bar, kP \\
\hline PER & $\begin{array}{l}\text { Percentage of extracellular release }= \\
\mathrm{PP}_{\mathrm{DOC}} /\left(\mathrm{PP}_{\mathrm{DOC}}+\mathrm{PP}_{\mathrm{POC}}\right)\end{array}$ & $\begin{array}{l}\text { Dimension- } \\
\text { less }\end{array}$ & $\%$ \\
\hline $\mathrm{P}_{\mathrm{DOC}}$ & Rate of DOC production & $\mathrm{ML}^{-2} \mathrm{~T}^{-1}$ & $\mathrm{~g} \mathrm{C} \mathrm{m}^{-2}$ year $^{-1}$ \\
\hline
\end{tabular}




\begin{tabular}{|c|c|c|c|}
\hline $\mathrm{P}_{\mathrm{DOC}<100}$ & Rate of production of $\mathrm{DOC}_{<100}$ & $\mathrm{ML}^{-2} \mathrm{~T}^{-1}$ & $\mathrm{~g} \mathrm{C} \mathrm{m}^{-2}$ year $^{-1}$ \\
\hline $\mathrm{P}_{\mathrm{DOC}>100}$ & Rate of production of $\mathrm{DOC}_{>100}$ & $\mathrm{ML}^{-2} \mathrm{~T}^{-1}$ & $\mathrm{~g} \mathrm{C} \mathrm{m}^{-2}$ year $^{-1}$ \\
\hline $\mathrm{P}_{\mathrm{POC}}$ & Rate of production of $\mathrm{POC}$ & $\mathrm{ML}^{-2} \mathrm{~T}^{-1}$ & $\mathrm{~g} \mathrm{C} \mathrm{m}^{-2}$ year $^{-1}$ \\
\hline POC & Particulate organic carbon & $\mathrm{ML}^{-2}$ & $\mathrm{~g} \mathrm{C} \mathrm{m}^{-2}$ \\
\hline POM & Particulate organic matter & $\mathrm{ML}^{-2}$ & $\mathrm{~g} \mathrm{~m}^{-2}$ \\
\hline PP & Primary production & $\mathrm{ML}^{-2} \mathrm{~T}^{-1}$ & $\mathrm{~g} \mathrm{C} \mathrm{m}^{-2}$ year $^{-1}$ \\
\hline $\mathrm{PP}_{\mathrm{DOC}}$ & Dissolved fraction of PP & $\mathrm{ML}^{-2} \mathrm{~T}^{-1}$ & $\mathrm{~g} \mathrm{C} \mathrm{m}^{-2}$ year $^{-1}$ \\
\hline $\mathrm{PP}_{\mathrm{POC}}$ & Particulate fraction of PP & $\mathrm{ML}^{-2} \mathrm{~T}^{-1}$ & $\mathrm{gC} \mathrm{m}^{-2}$ year $^{-1}$ \\
\hline RDOC & Refractory DOC & & $\mathrm{g} \mathrm{C} \mathrm{m}^{-2}$ \\
\hline SLDOC & Semi-labile DOC & $\mathrm{ML}^{-2}$ & $\mathrm{~g} \mathrm{C} \mathrm{m}^{-2}$ \\
\hline SRDOC & Semi-refractory DOC & $\mathrm{ML}^{-2}$ & $\mathrm{~g} \mathrm{C} \mathrm{m}^{-2}$ \\
\hline TA & see $A_{\mathrm{T}}$ & $\mathrm{NM}^{-1}$ & \\
\hline $\mathrm{TCO}_{2}$ & Total $\mathrm{CO}_{2} ;$ see $C_{\mathrm{T}}$ & $\mathrm{ML}^{-2}$ & \\
\hline URDOC & Ultra-refractory DC & $\mathrm{ML}^{-2}$ & $\mathrm{~g} \mathrm{C} \mathrm{m}^{-2}$ \\
\hline UV & Ultraviolet & $\mathrm{MT}^{-3}, \mathrm{~L}^{-2} \mathrm{~T}^{-1}$ & $\begin{array}{c}\mathrm{W} \mathrm{m}^{-2} \\
\text { mol photons } \mathrm{m}^{-2} \mathrm{~s}^{-1}\end{array}$ \\
\hline$z_{e}$ & Depth of carbon export & $\mathrm{L}$ & $\mathrm{m}$ \\
\hline$z_{d}$ & $e$-folding depth, where $F_{s}=0.37 F_{e}$ & $\mathrm{~L}$ & $\mathrm{~m}$ \\
\hline$z_{s}$ & Depth of carbon sequestration & $\mathrm{L}$ & $\mathrm{m}$ \\
\hline$\sum \mathrm{CO}_{2}$ & Total $\mathrm{CO}_{2} ;$ see $C_{\mathrm{T}}$ & & \\
\hline
\end{tabular}

* Alternative units to g C m${ }^{-2}\left[\mathrm{ML}^{-2}\right]$ and g C m${ }^{-2}$ year ${ }^{-1}\left[\mathrm{ML}^{-2} \mathrm{~T}^{-1}\right]$ are mol $\mathrm{C} \mathrm{m}^{-2}\left[\mathrm{NL}^{-2}\right]$ and mol C m ${ }^{-2}$ year $^{-11}\left[\mathrm{NL}^{-2} \mathrm{~T}^{-1}\right]$, respectively. 
Table 2. Grouping under various topics and sub-topics of definitions of terms, expressions and concepts given in the text, and sections of the text where these are discussed.

Topics and sub-topics: definitions

Section of

this text

\section{The three vertical ocean carbon pumps}

1.1. Concept of ocean carbon pumps. The ocean carbon pumps maintain the vertical gradient of $C_{\mathrm{T}}{ }^{1}$ that exists in the World Ocean. The global mean $C_{\mathrm{T}}$ in deep waters below $1200 \mathrm{~m}$ is higher than in the surface mixed layer, i.e. 2284 and $2012 \mu \mathrm{mol} \mathrm{kg}{ }^{-1}$, respectively. This requires that physical, chemical and biological processes counteract the continuous erosion by diffusive ocean mixing ${ }^{2}$ of the vertical differences in the concentration of $C_{\mathrm{T}}$. The ocean carbon pumps have an important effect on the air-sea $\mathrm{CO}_{2}$ fluxes on century time scales (IPCC 2013, Section 6.3.2.5.5).

\subsection{Three vertical ocean carbon pumps. Three vertical pumps contribute to}

maintaining the vertical $C_{\mathrm{T}}$ gradient $^{3}$ : (1) the solubility pump, (2) the carbonate pump ${ }^{4}$, and (3) the soft-tissue pump (also called organic carbon pump, but more generally biological carbon pump ${ }^{5}$, BCP).

\subsection{Mechanisms of the three vertical ocean carbon pumps. (1) In the solubility} pump, the dissolution of atmospheric $\mathrm{CO}_{2}$ in surface waters is followed by deep mixing of the $\mathrm{CO}_{2}$-rich water. (2) In the carbonate pump, the bio-precipitation

${ }^{1} C_{\mathrm{T}}=\mathrm{CO}_{2}$ (dissolved) $+\mathrm{H}_{2} \mathrm{CO}_{3}+\mathrm{HCO}_{3}{ }^{-}+\mathrm{CO}_{3}{ }^{2-}$. The concept of ocean carbon pumps was proposed by Volk and Hoffert (1985).

2 The mixing timescale of the ocean is $\sim 1000$ years.

${ }^{3}$ The three vertical carbon pumps were defined by Volk and Hoffert (1985).

${ }^{4}$ Also called carbonate counter-pump, where the prefix "counter" refers to the fact that the precipitation of $\mathrm{CaCO}_{3}$ in the ocean is accompanied by the release of $\mathrm{CO}_{2}$ to surrounding waters, and thus the atmosphere. This release contributes to maintain the vertical $C_{\mathrm{T}}$ gradient by decreasing sea-surface $C_{\mathrm{T}}$.

5 The expression biological carbon pump may refer to either the organic component of the ocean carbon pump only, or both the organic and $\mathrm{CaCO}_{3}$ components. Volk \& Hoffert (1985) and Passow \& Carlson (2012) used biological carbon pump for the sum of the two components. In this review, biological carbon pump refers only to the organic component, consistent with the Glossary in IPCC (2013, Annex III). 
of $\mathrm{CaCO}_{3}$ in the upper water column is accompanied by the release of $\mathrm{CO}_{2}$ to the surrounding waters, and from there to the atmosphere, and followed by the sinking of bio-mineral particles to depth. (3) In the biological pump, the photosynthetic uptake of inorganic carbon and synthesis of organic carbon by phytoplankton, and the transformation of this carbon by the pelagic food web in the euphotic zone (e.g. lysis, grazing, respiration, incorporation into larger particles) are followed by downward transfer of organic carbon (POC plus DOC) into deep waters.

1.4. General mechanism of the vertical ocean carbon pumps. The mechanism

of the three vertical pumps includes both the downward export of carbon from the surface ocean (i.e. the deepest of either the base of the euphotic zone or the seasonal surface mixed layer), and the downward transfer of the exported carbon into deep waters ( i.e. below the maximum depth of the permanent pycnovline of ca. $1000 \mathrm{~m}^{6}$ ). In this review, the downward transfer of carbon from the surface ocean that does not reach deep waters (i.e. bottom of the permanent pycnocline) is called carbon export. The vertical carbon pumps (sensu stricto, Volk and Hoffert, 1985) maintain the vertical $C_{\mathrm{T}}$ gradient by transferring (and thus effectively sequestering) carbon below the permanent pycnocline.

1.5. Magnitudes and dimensions of the three ocean carbon pumps. The physical dimensions of the three vertical ocean carbon pumps are $\left[\mathrm{ML}^{-2} \mathrm{~T}^{-1}\right]$, and the units in most oceanographic studies are $\mathrm{g} \mathrm{C} \mathrm{m}^{-2}$ year $^{-1}$ or mol C m ${ }^{-2}$ year ${ }^{-1}$, or for the whole ocean, $\mathrm{Pg} \mathrm{C}_{\text {year }}^{-1}$ or Gt $\mathrm{C}$ year ${ }^{-1}$ or Pmol C year ${ }^{-1}$. The solubility, carbonate and biological pumps transfer downwards DIC, $\mathrm{CaCO}_{3}$ and organic carbon, respectively, and the carbonate pump also transfers upwards $\mathrm{CO}_{2}$ to the atmosphere. The magnitude of the solubility pump is the rate of DIC transfer to depth. The magnitude of the carbonate pump is the rate of transfer of $\mathrm{CaCO}_{3}$ (and the $\mathrm{HCO}_{3}{ }^{-}$resulting from

\footnotetext{
${ }^{6}$ This depth of $1000 \mathrm{~m}$ is operationally equivalent to the $1200 \mathrm{~m}$ depth horizon that separates the upper water column with an average $C_{\mathrm{T}}$ concentration of $2012 \mu \mathrm{mol} \mathrm{kg}^{-1}$ from the deep waters with $2284 \mu \mathrm{mol} \mathrm{kg}{ }^{-1}$ (Volk and Hoffert, 1985).
} 
its dissociation) into deep waters plus the rate of transfer of $\mathrm{CO}_{2}$ into the atmosphere. The magnitude of the biological pump is the rate of transfer of organic carbon (and the $\mathrm{CO}_{2}$ resulting from its remineralisation) to depth.

\section{The ocean microbial carbon pump}

2.1. Dissolved organic carbon. Five fractions of dissolved organic carbon

$(D O C)$ have been identified in the ocean based on their lifetimes ${ }^{7}:(1)$ labile DOC (LDOC; average lifetime: hours to days), (2) semi-labile DOC (SLDOC; ca. 1.5 years), (3) semi-refractory DOC (SRDOC; ca. 20 years), (4) refractory DOC (RDOC; ca. 16000 years), and (5) ultra-refractory DOC (URDOC; ca. 40000 years). The lifetimes of the DOC fractions (from a few hours to tens of thousands of years) are part of a continuum.

2.2. Microbial carbon pump. The suite of marine microbial processes that lead to the production of longer-lived DOC fractions is called microbial carbon pump (MCP) ${ }^{8}$. Although, the MCP concept was not defined initially in the same terms, or expressed in the same units as the three vertical carbon pumps (Definition 1.5), the MCP has the same fundamental characteristic as the three other carbon pumps in that it maintains a gradient in concentration of carbon compounds. In the MCP case, the gradient is between DOC with average lifetime shorter and longer than 100 years $\left(\mathrm{DOC}_{<100}\right.$ and $\mathrm{DOC}_{>100}$, respectively), and is maintained against the continuous degradation of $\mathrm{DOC}_{>100}$, mostly by photochemical transformation. However, the MCP differs from the three vertical carbon pumps in that it maintains a gradient in concentration of dissolved organic carbon, whereas the other pumps maintain the vertical gradient in concentration of dissolved inorganic carbon.

\footnotetext{
${ }^{7}$ The five DOC fractions and their characteristics were defined by Hansell (2013).

${ }^{8}$ The concept of microbial carbon pump was proposed by Jiao et al. (2010, 2011). By calling this carbon pump microbial, the authors assumed that the production of the longer-lived DOC fractions (i.e. SRDOC, RDOC, and URDOC) largely resulted from the activity of marine pelagic microbes, i.e. unicellular planktonic organisms and viruses.
} 
suite of marine microbial processes leading to the production of the longerlived DOC fractions (i.e. Definition 2.2), the magnitude of the MCP is defined as the rate of production of longer-lived DOC, i.e. $P_{D O C>100}$. The dimensions are $\left[\mathrm{ML}^{-2} \mathrm{~T}^{-1}\right]$ and the units $\mathrm{g} \mathrm{C} \mathrm{m}^{-2}$ year ${ }^{-1}$ or mol $\mathrm{C} \mathrm{m}^{-2}$ year ${ }^{-1}$, or for the whole ocean, Pg C year ${ }^{-1}$ or Pmol C year ${ }^{-1}$, identical to the dimensions and units of the three vertical ocean carbon pumps (Definition 1.5).

2.4. Spatial redistribution of SRDOC, RDOC and URDOC. The concentration of total DOC is higher in surface waters, where all DOC fractions are present, than below, where only the long-lived DOC is thought to occur. Below $\sim 100 \mathrm{~m}$, there is production of DOC by food-web activities, but the concentrations of LDOC and SLDOC (and SRDOC at low latitudes) are generally low because this DOC is recycled (i.e. consumed, and partly repackaged into $\mathrm{POC}$ or metabolised to $\mathrm{CO}_{2}$ and longer-lived DOC) more rapidly than the $\sim 1000$-year mixing timescale of the ocean and consequently does not accumulate. In contrast, micromolar concentrations of longer-lived DOC fractions occur in significant amounts at all depths, with latitudinal variations, and this indicates that the longer-lived DOC fractions (i.e. DOC $>100$ ) are redistributed vertically by various physical and biological mechanisms.

\section{Carbon sequestration}

3.1. Carbon sequestration. Carbon sequestration is the addition of inorganic or organic carbon to a terrestrial or aquatic reservoir (i.e. to a component of the climate system other than the atmosphere), where a reservoir has the capacity to accumulate, store or release carbon. The carbon reservoirs considered here are the deep ocean waters, marine sediments, and long-lived DOC. 9 .

\subsection{Duration of sequestration. Because carbon is transformed by several} natural cycles that operate over a range of different timescales, carbon sequestration can be of different durations: up to hundreds of millions of year

\footnotetext{
${ }^{9}$ Combination of definitions given for sequestration, uptake, and reservoir in the Glossary of IPCC (2013, Annex III). According to that glossary, the word pool is an equivalent term to reservoir, although the definition of pool often includes the atmosphere.
} 
in the carbonate-silicate cycle, less than one million years in the carbonate

cycle, thousands or tens of thousands of years for long-lived marine DOC, and up to one thousand years when transferred into deep ocean waters. As a pragmatic rule, the present review considers that carbon is sequestered when it is stored or accumulated in a reservoir for at least 100 years.

3.3. Natural carbon sequestration. Carbon dioxide can be captured and removed from the atmosphere through naturally occurring biochemical, biological, chemical and/or physical processes, this $\mathrm{CO}_{2}$ being sequestered in natural reservoirs.

\subsection{Carbon dioxide removal methods. Carbon Dioxide Removal (CDR)}

methods are a set of techniques that aim to remove $\mathrm{CO}_{2}$ directly from the atmosphere by either increasing natural sinks for carbon or using chemical or geochemical engineering approaches to remove the $\mathrm{CO}_{2}$, with the intent of reducing the atmospheric $\mathrm{CO}_{2}$ concentration. The $\mathrm{CDR}$ methods may involve the ocean (e.g. iron fertilisation), land (e.g. large-scale reforestation), and technical systems (e.g. direct capture of $\mathrm{CO}_{2}$ from the atmosphere using engineered chemical means). Some CDR methods fall under the category of geoengineering, depending on the magnitude, scale, and impact of the particular CDR activities. (IPCC 2013, Annex III, Glossary).

\section{The ocean carbon pumps and marine carbon sequestration}

4.1. Carbon sequestration in deep waters. Because the carbon that reaches deep waters does not return as $C_{\mathrm{T}}$ to surface waters where $\mathrm{CO}_{2}$ can be exchanged with the atmosphere within 100 years, this carbon is considered to be sequestered (Definition 3.2 above).

4.2. Downward transfer of carbon by the vertical ocean carbon pumps. The three vertical ocean carbon pumps transfer export carbon into deep waters i.e. below the maximum depth of the permanent pycnocline (Definition 1.4 above). 
4.3. The vertical ocean carbon pumps and marine carbon sequestration. As a

consequence of Definitions 4.1 and 4.2, the three vertical ocean carbon pumps sequester carbon in the deep waters or sediment reservoirs, in different forms: the deep ocean circulation (average timescale: ca. 1000 years), where carbon is sequestered as dissolved $\mathrm{CO}_{2}$ or DOC; sediments, where inorganic $\left(\mathrm{CaCO}_{3}\right)$ and organic carbon are sequestered for thousands of years; and the lithosphere, where carbon is sequestered for millions of years in carbonate rocks and as fossil organic carbon (e.g. kerogen and hydrocarbons). Sequestered organic carbon includes methane hydrate (i.e. clathrate). On continental shelves and slopes, carbon may be stored in shallow-water $\mathrm{CaCO}_{3}$ reefs, or delivered and stored into sediments $<1000 \mathrm{~m}$ depth.

4.4. The MCP and marine carbon sequestration. the MCP contributes to carbon sequestration through the biochemical transfer of carbon from organic compounds with a lifetime $<100$ years to DOC fractions with a lifetime $>100$ years, i.e. URDOC, RDOC, and part of SRDOC. Micromolar concentrations of longer-lived DOC fractions occur in significant amounts at all depths in the ocean. In this review, application of the MCP concept is limited to the suite of processes that transfer carbon to $D O C_{>100}$.

\section{Difference between the biological and the microbial carbon pumps}

\subsection{Sequestration mechanism of the $B C P$. The $B C P$, as do the two other} vertical ocean carbon pumps, sequesters carbon by transferring organic matter into deep waters (Definition 4.3). The BCP leads to the sequestration into different reservoirs below ca. $1000 \mathrm{~m}$ of carbon supplied by sinking or vertically transported POC and vertically mixed DOC that is not associated with the MCP (i.e. that has not been transformed into long-lived DOC by the $\mathrm{MCP})$. In other words, the vertical distribution of the carbon sequestered through the $B C P$ is depth dependent.

\subsection{Sequestration mechanism of the MCP. The $M C P$ sequesters carbon by} transferring it to $D O C_{>100}$. Because the long-lived DOC reservoir exists at all 
depths in the ocean (Definition 4.4), the vertical distribution of the carbon sequestered by the MCP is depth independent.

5.3. BCP and the MCP are distinct. Even if the depth redistribution mechanisms of $\mathrm{DOC}_{>100}$ overlap with the vertical transfer of carbon by the $\mathrm{BCP}$, the two ocean carbon pumps are distinct. Carbon sequestration by the $\mathrm{MCP}$ is a consequence of the production of $\mathrm{DOC}_{>100}$ and is independent of its vertical redistribution. In contrast, carbon sequestration by the BCP is governed by the downward transfer of organic carbon compounds.

5.4. Assignment of carbon to the BCP or the MCP. Further to Definitions 5.1 to

\section{3 , the MCP sequesters carbon by biochemical transfer to the DOC $>100$} reservoir, whereas the $B C P$ sequesters carbon by downward transfer into deep carbon reservoirs. In cases when carbon is sequestered at depth by the $\mathrm{BCP}$, its further deep-water microbial transformation into $\mathrm{DOC}_{>100}$ would not change the initial assignment of this carbon to the BCP. Similarly, when carbon is sequestered by the MCP above $1000 \mathrm{~m}$, its further vertical transport below $1000 \mathrm{~m}$ would not change the initial assignment of this carbon to the MCP. This operational first-time-sequestration criterion prevents organic carbon fluxes from being assigned to both the $\mathrm{BCP}$ and the MCP 
Table 3. Calculation of $\mathrm{P}_{\mathrm{DOC}<100}$ and $\mathrm{P}_{\mathrm{DOC}>100}$. The value of $\mathrm{P}_{\mathrm{DOC}>100}$ provides an estimate of the magnitude of the MCP. Columns: DOC fractions, average lifetimes, and inventory and annual production (DOC Prod) in the World Ocean from (Hansell, 2013; his Table 1); the limits of lifetime classes were set in such a way as to subdivide equally (on a logarithmic scale) the overall range of average lifetimes (i.e. from $10^{-3}$ to $10^{4.2}$ years, excluding URDOC; see Fig. 2). The inventory and $\mathrm{P}_{\mathrm{DOC}}$ values for $\mathrm{DOC}_{<100}$ and $\mathrm{DOC}_{>100}$ were obtained by linearly dividing SRDOC into two fractions with lifetimes of $10^{0.6}$ to $10^{2}$ and $10^{2}$ to $10^{3}$ years, respectively, and summing up the values corresponding to $<10^{2}$ and $\geq 10^{2}$ years from all fractions (excluding URDOC), respectively.

\begin{tabular}{|c|c|c|c|c|}
\hline $\begin{array}{l}\text { DOC } \\
\text { fraction }\end{array}$ & $\begin{array}{l}\text { Average lifetime } \\
\text { (years) }\end{array}$ & $\begin{array}{l}\text { Limits of lifetime } \\
\text { classes (years) }\end{array}$ & $\begin{array}{l}\text { Inventory } \\
(\mathrm{PgC})\end{array}$ & $\begin{array}{l}\mathrm{P}_{\mathrm{DOC}} \\
\left(\mathrm{PgC}_{\text {year }^{-1}}\right)\end{array}$ \\
\hline LDOC & $0.001=10^{-3}$ & $10^{-4.2}$ to $10^{-1.8}$ & $<0.2$ & 25 \\
\hline SLDOC & $1.5=10^{0.18}$ & $10^{-1.8}$ to $10^{0.6}$ & 6 & 3.40 \\
\hline SRDOC & $205=10^{1.3}$ & $10^{0.6}$ to $10^{3}$ & $14=8+6$ & $\begin{array}{l}0.34= \\
0.20+0.14\end{array}$ \\
\hline RDOC & $16000=10^{4.2}$ & $10^{3}$ to $10^{5.4}$ & 630 & 0.043 \\
\hline URDOC & $40000=10^{4.6}$ & & $>12$ & $1.2 \times 10^{-5}$ \\
\hline $\mathrm{DOC}_{<100}$ & $<100$ & $10^{-4.2}$ to $10^{2}$ & $\begin{array}{l}<0.2+6+8 \\
=14\end{array}$ & $\begin{array}{l}25+3.40+0.20 \\
=28.6\end{array}$ \\
\hline $\mathrm{DOC}_{>100}$ & & $10^{2}$ to $10^{5.4}$ & $\begin{array}{l}6+630= \\
636\end{array}$ & $\begin{array}{l}0.14+0.04= \\
0.18\end{array}$ \\
\hline
\end{tabular}


Table 4. Potential effects of climate-driven changes in the ocean environment on microbial variables and carbon sequestration by the MCP, described in Section 7 (numbers at the beginning of rows: sub-Sections of the text where the responses of microbial variables and MCP carbon sequestration are explained). The three entries under "Water-column stratification" detail three changes (bullets) that may occur as a result of increasing stratification. Estimates of carbon sequestration by the MCP correspond to possible net effects of environmental changes on production of RDOC and SRDOC with a lifetime $\geq 100$ years $\left(\mathrm{P}_{\mathrm{DOC}>100}\right)$. Increase: $\uparrow$; decrease: $\downarrow$.

\begin{tabular}{llc}
\hline Environmental & Responses of microbial variables to the & Carbon sequestration \\
factor & changing environment & by the MCP
\end{tabular}

\subsection{Surface-ocean temperature $\uparrow$}

Shift from POC to DOC production $\uparrow$

\subsection{Water-column stratification $\uparrow$}

- near-surface retention $\uparrow$ (+ cloud cover $\downarrow$ )

- oligotrophy $\uparrow$

- phytoplankton mean size $\downarrow$

7.3. POC production $\downarrow$

\subsection{Thermohaline} circulation and cloud cover $\downarrow$
Higher conversion of labile forms of DOC into SRDOC and RDOC by photodegradation

PER does not vary as a function of the nutrient status of the system

Decreased production of SRDOC and RDOC
No conclusive effect

Lower production of SRDOC or RDOC by prokaryotic POC solubilisation

Higher photodegradation of SRDOC and RDOC

$\downarrow$

7.5. $\mathrm{pH} \downarrow$ (i.e. ocean $\quad$ Increased production of DOC (possibly 


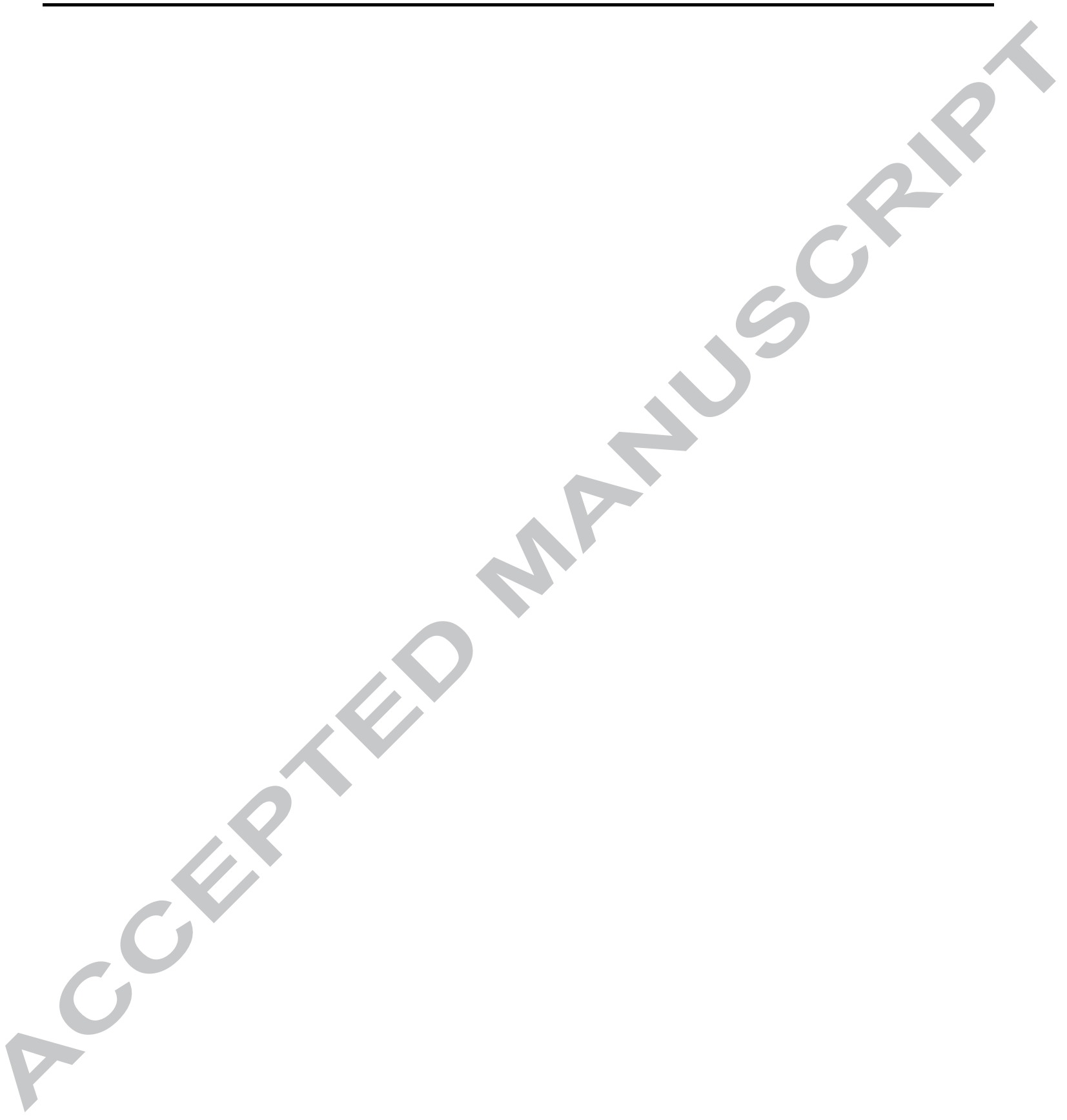

